University of Nebraska - Lincoln

DigitalCommons@University of Nebraska - Lincoln

\title{
A satellite-based assessment of the relative contribution of hydroclimatic variables on vegetation growth in global agricultural and non-agricultural regions
}

\author{
Akarsh Asoka \\ Indian Institute of Technology Gandhinagar \\ Brian Wardlow \\ University of Nebraska - Lincoln, bwardlow2@unl.edu \\ Tsegaye Tadesse \\ University of Nebraska - Lincoln, ttadesse2@unl.edu \\ Matthew Huber \\ Purdue University \\ Vimal Mishra \\ Indian Institute of Technology (IIT)
}

Follow this and additional works at: https://digitalcommons.unl.edu/natrespapers

Part of the Natural Resources and Conservation Commons, Natural Resources Management and Policy Commons, and the Other Environmental Sciences Commons

Asoka, Akarsh; Wardlow, Brian; Tadesse, Tsegaye; Huber, Matthew; and Mishra, Vimal, "A satellite-based assessment of the relative contribution of hydroclimatic variables on vegetation growth in global agricultural and non-agricultural regions" (2021). Papers in Natural Resources. 1403.

https://digitalcommons.unl.edu/natrespapers/1403

This Article is brought to you for free and open access by the Natural Resources, School of at DigitalCommons@University of Nebraska - Lincoln. It has been accepted for inclusion in Papers in Natural Resources by an authorized administrator of DigitalCommons@University of Nebraska - Lincoln. 


\section{JGR Atmospheres}

\author{
RESEARCH ARTICLE \\ 10.1029/2020JD033228 \\ Key Points: \\ - A significant $(p$-value $<0.05)$ \\ greening has occurred in the \\ agricultural ecosystems of India and \\ Brazil during 2003-2014 \\ - A significant greening occurred \\ only in India and China in the \\ nonagricultural ecosystems during \\ 2003-2014 \\ - Day and night-time land surface \\ temperature are the major \\ contributors to vegetation growth \\ over the two-thirds of the globe
}

Supporting Information:

- Supporting Information S1

Correspondence to:

V. Mishra,

vmishra@iitgn.ac.in

Citation:

Asoka, A., Wardlow, B., Tsegaye, T., Huber, M., \& Mishra, V. (2021). A satellite-based assessment of the relative contribution of hydroclimatic variables on vegetation growth in global agricultural and nonagricultural regions. Journal of Geophysical Research: Atmospheres, 126, e2020JD033228. https://doi. org/10.1029/2020JD033228

Received 4 JUN 2020

Accepted 6 JAN 2021

\section{A Satellite-Based Assessment of the Relative Contribution of Hydroclimatic Variables on Vegetation Growth in Global Agricultural and Nonagricultural Regions}

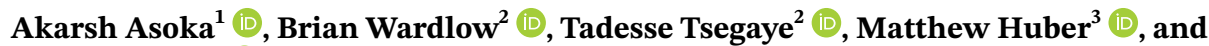 \\ Vimal Mishra ${ }^{1}$ (1) \\ ${ }^{1}$ Civil Engineering and Earth Sciences, Indian Institute of Technology Gandhinagar, Gandhinagar, India, ${ }^{2}$ School of \\ Natural Resources, University of Nebraska Lincoln, Lincoln, NE, USA, ${ }^{3}$ Earth, Atmospheric, and Planetary Sciences, \\ Purdue University, West Lafayette, IN, USA
}

Abstract Vegetation growth plays a crucial role in the carbon cycle and climate change mitigation. However, the relative contribution of hydroclimatic variables (relative humidity, terrestrial water storage, day and night-time land surface temperatures) on vegetation growth of agricultural and nonagricultural areas at the global scale remains unexplored. Using satellite-based datasets, we examined the changes in Normalized Difference Vegetation Index (NDVI) and the four hydroclimatic variables during 2003-2014. Also, the relative contribution of the four hydroclimatic variables on vegetation growth in agricultural and nonagricultural areas was estimated. A significant (p-value $<0.05)$ greening has occurred in the agricultural regions of India and Brazil during 2003-2014. Whereas in nonagriculture areas, a considerable greening occurred only in India and China during the 2003-2014 period. Among the four hydroclimatic variables, both day-time and night-time land surface temperature are the significant contributors of vegetation growth in the two-thirds of the global landmass. Terrestrial water storage is a substantial contributor to the vegetation growth in the tropics and subtropics. Night-time land surface temperature is strongly associated with the vegetation growth in the colder regions. The hydroclimatic variables do not explain the considerable amount of the total variance of vegetation growth over the agricultural areas in China, which is due to human agricultural management practices. Generally, the response of hydroclimate variables on vegetation growth in the agricultural and nonagricultural areas has significant implications in many areas, including food security, carbon sequestration, water resource management, and climate change.

\section{Introduction}

Changes and variability in vegetation growth are driven by anthropogenic and natural factors (Chen et al., 2019; Nemani et al., 2003; Zhao et al., 2018). Understanding the drivers of vegetation growth is vital to evaluate its role in climate change mitigation and on carbon cycle (Keith et al., 2009; Schmidhuber \& Tubiello, 2007; Zeng et al., 2017; Zhao et al., 2018). Over the last few decades, global environmental change has rapidly altered the vegetation dynamics overland with its implications on earth system and ecosystem services (Zhu et al., 2016). $\mathrm{CO}_{2}$ fertilization has been one of the primary drivers of the long-term vegetation growth over the tropics (Zhao et al., 2018). The rise in air temperature due to anthropogenic warming has contributed to vegetation growth in most of the high latitude regions (Zhu et al., 2016). Global mean growing season normalized difference vegetation index (NDVI) has increased during 1982-2013, which was driven by temperature (high latitudes), water (arid and semi-arid regions), and radiation (Amazon and southern Asia, Zhao et al., 2018). Apart from the natural drivers of vegetation growth (temperature, water, and radiation), human land management associated with fertilizer and irrigation applications played a significant role in the vegetation growth in areas such as India and China during 2000-2017, (Chen et al., 2019).

Vegetation growth and its driving factors have received considerable attention in the past. For instance, Nemani et al. (2003) reported that climate change in the northern mid and high latitudes enhanced plant growth. Climate change contributed to a $6 \%$ rise in the net primary productivity during 1982-1999, primarily due to decreased cloud cover and increased solar radiation (Nemani et al., 2003). Greenhouse gas emissions (c) 2021. American Geophysical Union. All Rights Reserved. 
(GHG) explain about $66 \%$ of the total variance in the observed trend of vegetation growth, and $\mathrm{CO}_{2}$ fertilization effect explains about 70\% of the observed greening trend during 1982-2013 (Zhao et al., 2018). There had been a persistent and widespread increase in growing season greening over $25 \%-50 \%$ of the global vegetated land surface (Nemani et al., 2003). Apart from climate change, climate variability also influences vegetation growth. For example, Gonsamo et al. (2016) examined the contribution of climate variability on global vegetation productivity during 1982-2011 and found that El Nino Southern Oscillation (ENSO) variations have substantial control on vegetation productivity through their influence on air temperature. On the other hand, Zhao et al. (2018) reported that ENSO is the leading climatic driver of interannual variability in vegetation growth globally. Overall, climate change, climate variability, and $\mathrm{CO}_{2}$ fertilization are the crucial drivers of long-term trends in vegetation growth.

Hydroclimatic factors can have a different contribution to vegetation growth in different regions of the world. For instance, increasing temperature due to climate change is positively associated with vegetation growth in northern latitudes. In contrast, warming and moisture deficits can lead to large-scale droughts, causing a decline in net primary productivity (Fosu et al., 2017; Zhao \& Running, 2010). While most of the previous studies considered daily mean air temperature (Zhao et al., 2018; Zhu et al., 2016), vegetation response to day- and night-time temperature can be asymmetrical as photosynthesis is positively associated with day-time temperature. At the same time, plant respiration is affected by both day and night-time temperature (Peng et al., 2013). Several previous studies evaluated the role of natural and anthropogenic factors on vegetation growth (Brown et al., 2012; Chen et al., 2019; Nemani et al., 2003; Peng et al., 2013; Wu et al., 2015; Zhao et al., 2018; Zhu et al., 2016). However, these studies did not consider the influence of day and night-time land surface temperatures, terrestrial water storage and relative humidity together to identify their relative contribution to vegetation growth in agricultural and nonagricultural areas. Therefore, the crucial interaction between day and night-time land surface temperature with water availability and relative humidity on vegetation growth in agricultural and nonagricultural regions is not well examined.

Both climate variability and anthropogenic effects (e.g., fertilizer application, irrigation and land-use change) can profoundly impact vegetation growth in agricultural and nonagricultural regions. Zhao et al. (2018) reported that globally nitrogen deposition and land-use change did not contribute significantly to the observed trend in vegetation growth during 1982-2013. However, the contribution of anthropogenic factors at the regional scale can be substantial. For instance, Chen et al. (2019) reported that land-use management contributed to significant greening over China and India during 2000-2017. This rise in greening over China and India occurred because of an increase in the harvested area due to multicropping, fertilizer, and irrigation from surface and groundwater resources (Chen et al., 2019). Piao et al. (2020) also reported the pronounced greening over the farmed or afforested areas of China and India. They (Piao et al., 2020) found that the greening in the areas of the low human footprint is mainly driven by global change through $\mathrm{CO}_{2}$ fertilization.

Understanding of the regional scale drivers of vegetation growth is essential for climate change mitigation. However, most of the previous studies (Nemani et al., 2003; Seddon et al., 2016; Zhao et al., 2018; Zhao \& Running, 2010) were conducted at the global scale and did not consider the regional-scale drivers of vegetation growth. Moreover, the human footprint in vegetation growth is identified by considering the contribution of climatic and anthropogenic drivers separately for the agricultural and nonagricultural regions. For instance, in agricultural-dominated areas, land-use management-related factors (e.g., fertilizer application, irrigation, multicropping system) can be significant drivers of vegetation growth (Chen et al., 2019; Piao et al., 2020). Moreover, the climatic factors other than $\mathrm{CO}_{2}$ fertilization can contribute more to year-to-year variability, while $\mathrm{CO}_{2}$ fertilization can be a significant driver of the long-term trends in vegetation growth (Zhao et al., 2018; Zhu et al., 2016). Our understanding of the relative contribution of hydroclimatic variables (temperature, water availability and relative humidity) on vegetation growth in the agricultural and nonagricultural regions remains limited (Chen et al., 2019; Zhao et al., 2018; Zhu et al., 2016).

In this study, satellite-based NDVI, relative humidity (RH), terrestrial water storage (TWS), and day and night-time land surface temperature (LSTD and LSTN) are analyzed to quantify their relative contribution to vegetation growth in agricultural and nonagricultural ecosystems during the 2003-2014 period at the global scale. We estimate observed changes in NDVI and the hydroclimatic variables during the study period across global agricultural and nonagricultural areas. This work addressed the following questions: 
(i) to what extent did NDVI and the four hydroclimatic variables change in global agricultural and the nonagricultural regions during 2003-2014, (ii) what is the relative contribution of the hydroclimatic variables on vegetation growth in the agricultural and nonagricultural areas? and (iii) Among $\mathrm{CO}_{2}$ fertilization and climate, which is the prominent driver of vegetation growth? We used satellite-based observations for 2003-2014 to address the first two questions. We use simulations from Land Use Model Intercomparison Project (LUMIP) to examine the role of $\mathrm{CO}_{2}$ fertilization and climate on vegetation growth.

\section{Data and Methods}

\subsection{Datasets}

We used monthly Normalized Difference Vegetation Index (NDVI) as a proxy to assess the role of hydroclimatic factors on vegetation growth (Asoka \& Mishra, 2015; Funk \& Brown, 2006). We obtained NDVI at $1^{\circ}$ spatial resolution from the MODIS Aqua (MYDVI005: https://disc.gsfc.nasa.gov/datasets/MYDVI_005/ summary) and Terra (MODVI005: https://disc.gsfc.nasa.gov/datasets/MODVI_005/summary) sensors during 2003-2014 (Huete et al., 1994). We used satellite-based, global datasets of relative humidity (RH), terrestrial water storage (TWS), day-time and night-time land surface temperatures (LSTD \& LSTN) to quantify their role on the vegetation growth in agriculture and nonagricultural regions throughout the world. Since satellite-based observations of NDVI and hydroclimatic variables are available for the 2003-2014 period, we limit our analysis to this short span only. Monthly surface relative humidity over equilibrium phase (\%) retrieved from NASA Atmospheric Infrared Sounder (AIRS; Aumann et al., 2003; Goldberg et al., 2003) and Advanced Microwave Sounding Unit (AMSU) onboard the NASA Aqua satellite was used. Specifically, AIRS relative humidity data (level 3 version 6) for the descending track with an equatorial crossing time of 1:30 a.m. (local time) was used (Farahmand et al., 2015; Tian et al., 2013). The relative humidity data is globally available at $1^{\circ}$ spatial and monthly temporal resolutions.

To examine the role of water availability on interannual variability of vegetation growth, satellite-based Gravity Recovery and Climate Experiment (GRACE) monthly terrestrial water storage anomaly data at $1^{\circ}$ spatial resolution (Landerer \& Swenson, 2012) was used. Specifically, the ensemble mean of terrestrial water storage anomaly product from NASA's Jet Propulsion Laboratory (JPL), Center for Space Research (CSR) at the University of Texas, and Deutsches GeoForschungs Zentrum (GFZ) was used to minimize uncertainty among different products. Day and night time monthly mean land surface temperature (LST) from MODIS Aqua (Day: MYD11CM1D and Night: MYD11CM1N); and Terra (Day: MOD11CM1D and Night: MOD11CM1N) at $1^{\circ}$ spatial resolution (https://disc.gsfc.nasa.gov/datasets/) was used. The MODIS day and night time LST (MOD11C3 and MYD11C3), available at $0.05^{\circ}$ resolution, is averaged within $1^{\circ}$ grid to produce the monthly product at a global scale. We obtained precipitation, maximum, and minimum temperatures (Tmax and Tmin) from Princeton Global Meteorological Forcing Data set (Sheffield et al., 2006). Gridded precipitation and temperature are available for the $1948-2016$ period at $0.25^{\circ}$ spatial and daily temporal resolutions. We obtained the monthly deseasonalized atmospheric $\mathrm{CO}_{2}$ concentration from Mauna Loa observatory. Further details on the datasets used in our analysis are given in Table S1.

The MODIS global land cover climatology (Broxton et al., 2014; Friedl et al., 2010) at $500 \mathrm{~m}$ spatial resolution was used to identify agricultural and nonagricultural areas (Figure S1a). Since our analysis is based on a relatively short time period (2003-2014), we assume that the land cover changes during 2003-2014 are not considerable at the spatial resolution and scale of this analysis. Since vegetation growth can vary with the climate regimes, thermal zone data from the Food and Agriculture Organization (FAO, Global Agro-ecological Zones, GAEZ v3.0; FAO/IIASA, 2012) was used to estimate the changes in vegetation growth and their driving factors based on climate zones. The thermal zone data is available at five arc-minutes $(\sim 8 \mathrm{~km})$ based on a 1961-1990 baseline period, which divides the globe into 12 major zones. We reclassified the 12 thermal zones to seven major classes after merging similar zones (Figure S1b).

\subsection{Analysis Approach}

To examine the role of hydroclimatic variables in agricultural and nonagricultural regions, we selected 10 areas distributed across the world that included India, China, Russia, continental United States (CONUS), Canada, Brazil, Argentina, Australia, Europe and Africa to understand spatial patterns in vegetation growth 


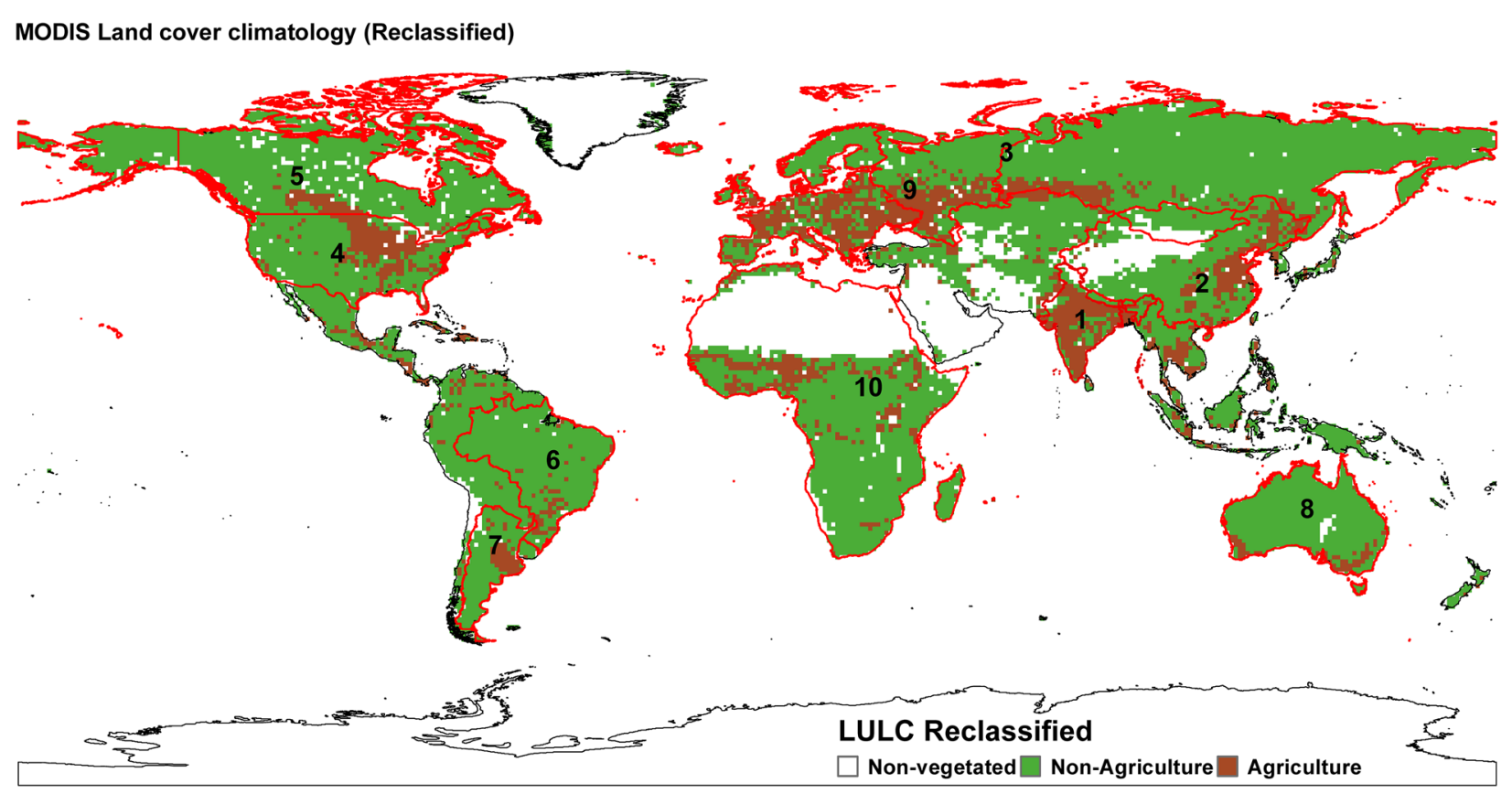

Figure 1. MODIS land cover climatology reclassified into nonvegetated (water bodies, snow cover, urban, and barren land), agricultural (Croplands and cropland/natural vegetation) and nonagricultural (woody savannas, savannas, open shrubs, mixed forests, grasslands, evergreen forests, deciduous forest and closed shrublands) areas. The boundaries in red color show the selected 10 regions: 1 India, 2: China, 3: Russia, 4: USA, 5: Canada, 6: Brazil, 7: Argentina, 8: Australia, 9: Europe, and 10: Africa.

and their driving factors (Figure 1). These 10 regions cover most of the vegetated areas across different climatic settings. Regionally aggregated vegetation in the agricultural and nonagricultural areas was considered to identify the predictors of vegetation anomaly. We spatially aggregated the MODIS landcover climatology data to $1 \times 1^{\circ}$ resolution based on majority class to identify the agricultural and nonagricultural grids. As anthropogenic factors (irrigation and fertilizer applications) can influence trend and variability of vegetation growth in the agricultural regions, croplands and cropland/natural vegetation classes from the MODIS land cover climatology were merged to identify the agricultural-dominated areas. All other vegetated pixels (including the woody savannas, savannas, open shrubs, mixed forests, grasslands, evergreen forests, deciduous forest and closed shrublands thematic classes in the MODIS land cover data product) were aggregated to form the nonagricultural class (Figure 1). All the nonvegetated (water bodies, snow cover, urban, and barren land) pixels were excluded from the analysis (Figure S1a and Figure 1). Pixels with the long-term (2003-2014) mean NDVI less than 0.1 were also excluded as they mostly represent nonvegetated regions.

Changes in NDVI and the other hydroclimatic variables were estimated using a nonparametric Mann-Kendall trend test (Kendall, 1975; Mann, 1945) and Sens's slope (Sen, 1968) method for the 2003-2014 period. The trend slope (per year) was estimated using the Mann-Kendall trend and Sen's slope method, which was multiplied by the duration (in years) to calculate the change. Changes were estimated on the annual, mean time-series of NDVI, relative humidity, terrestrial water storage, day-time land surface temperature and night-time land surface temperature with statistical significance at $5 \%$ level. Standardized indices of hydroclimatic variables and NDVI were derived at a 3-month time scale using the Standardized Drought Analysis Toolbox (SDAT, Farahmand et al., 2015; Farahmand \& AghaKouchak, 2015; Hao et al., 2014). SDAT produced temporally consistent nonparametric standardized indices that can be directly compared with each other (Farahmand \& AghaKouchak, 2015). Standardized indices were estimated after subtracting the long-term mean and divided by the standard deviation. This standardization removed the influence of seasonality. A three-month time interval was used for the analysis as it represents a seasonal time scale for vegetative growth and phenological cycle (Farahmand et al., 2015). After a careful quality check to avoid inconsistencies, gridded data with a temporally consistent time series containing more than $90 \%$ observations (considering missing data) available for 2003-2014 period, was used for the analysis. We removed a 
linear trend from the standardized indices of vegetation growth and hydroclimatic variables to estimate the relative contribution from hydroclimatic variables. The presence of a trend in variables can influence relative contribution due to serial correlation. We used the first difference of deseasonalized $\mathrm{CO}_{2}$ concentration $\left(\mathrm{CO}_{2}\right.$ growth rate) to derive a 3-month standardized index. We removed the previous months' $\mathrm{CO} 2$ concentration from each month to estimate the first difference and to exclude the influence of long-term trend. Further details on the $\mathrm{CO}_{2}$ concentration data can be obtained from the NOAA Earth System Research Lab (NOAA-ESRL: ftp://aftp.cmdl.noaa.gov/products/trends/co2/co2_mm_mlo.txt).

The relative contribution of climate and $\mathrm{CO}_{2}$ concentration on vegetation growth was evaluated using LAI simulations (as LAI and NDVI show a strong relationship) from the LS3MIP and LUMIP (van de Hurk et al., 2016; Lawrence et al., 2016). The LS3MIP protocol is used to assess the land surface, snow and soil moisture feedbacks on climate variability and climate change (van de Hurk et al., 2016). The LUMIP experiments aim to improve the understanding of land use/land cover change (LULCC) and land management (including $\mathrm{CO}_{2}$ fertilization) on climate, biogeochemical cycles and carbon, water and energy fluxes (Lawrence et al., 2016) within the framework of coupled model intercomparison project 6 (CMIP6). We used the LAI simulations from the Community Earth System Model (CESM) under the three experimental conditions defined within the LS3MIP and LUMIP protocols: Land-hist (LS3MIP), which provides historical simulations, Land- $\mathrm{CCO}_{2}$ (LUMIP), which is same as the land-hist experiment but the atmospheric $\mathrm{CO}_{2}$ concentration kept constant, and Land-CCLIM (LUMIP), which is same as the Land-hist but the climate kept constant. By comparing these cases, the relative influence of climate and $\mathrm{CO}_{2}$ can be estimated using LAI from Land-hist (LAI-HIST), Land-CCLIM (LAI-CCLIM), and Land-CCO (LAI-CCO $_{2}$ ). Here, we note that LAI (Land-hist) has the combined influence of climate and $\mathrm{CO}_{2}$. We estimated short-term (2003-2014) and long-term (1951-2015) changes in mean annual LAI for all the three scenarios (LAI-HIST, LAI-CCLIM, and LAI- $\mathrm{CCO}_{2}$ ) to estimate the contribution of $\mathrm{CO}_{2}$ on the changes in LAI.

\subsection{Relative Contribution}

Relative contribution (Bi, 2012; Grömping, 2006; Lindeman et al., 1980; Silber et al., 1995) of the four hydroclimate variables on interannual variability of vegetation growth was estimated based on the fraction of total variability $\left(R^{2}\right)$ in vegetation growth (NDVI) explained by each of the four hydroclimatic variables (Grömping, 2006). The relative importance of RH, TWS, LSTD, and LSTN was estimated for each grid cell at $95 \%$ confidence using 1000 bootstrap runs. The relative importance analysis was based on the method reported in Lindeman et al. (1980), which provides relative contribution regressors considering multicollinearity (Bi, 2012; Grömping, 2006).

\section{Results}

\subsection{Observed Changes in Vegetation and Hydroclimatic Variables}

First, the climatological mean of NDVI and the four hydroclimatic variables were used to evaluate their spatial variability across the globe (Figure 2). For example, the MODIS-based land cover climatology clearly shows the areas with high and low NDVI for the 2003-2014 period (Figures 2a and Table S2). Similarly, we find that mean relative humidity is lower in the Middle East and SubSaharian Africa regions with higher relative humidity found at the northern latitudes and in the tropics (Figure 2b). The terrestrial water storage climatology shows the low water availability in many regions of the northern hemisphere (Figure 2c). Day and night-time land surface temperatures are higher in tropics and lower in the northern latitudes (Figures $2 \mathrm{~d}$ and 2e).

Changes in NDVI in agriculture and nonagricultural regions and the four (relative humidity, terrestrial water storage, day-time land surface temperature, and night-time land surface temperature) hydroclimatic variables were calculated for the 2003-2014 study period as presented in Figure 3. A strong increase in NDVI was found in India, eastern China, Europe and the western part of Australia (Figure 3a and Figure S2). However, a statistically significant ( $p$-value $<0.05$ ) increase in NDVI only occurred over the agricultural areas in India and Brazil (Figure $3 \mathrm{f}$ and Figure S2). In contrast, a considerable decline in NDVI was found over agricultural areas over the CONUS (Figure 3 and Figure S2). NDVI of agricultural regions also declined in Canada and Argentina; however, the changes were not statistically significant at 5\% level. We 

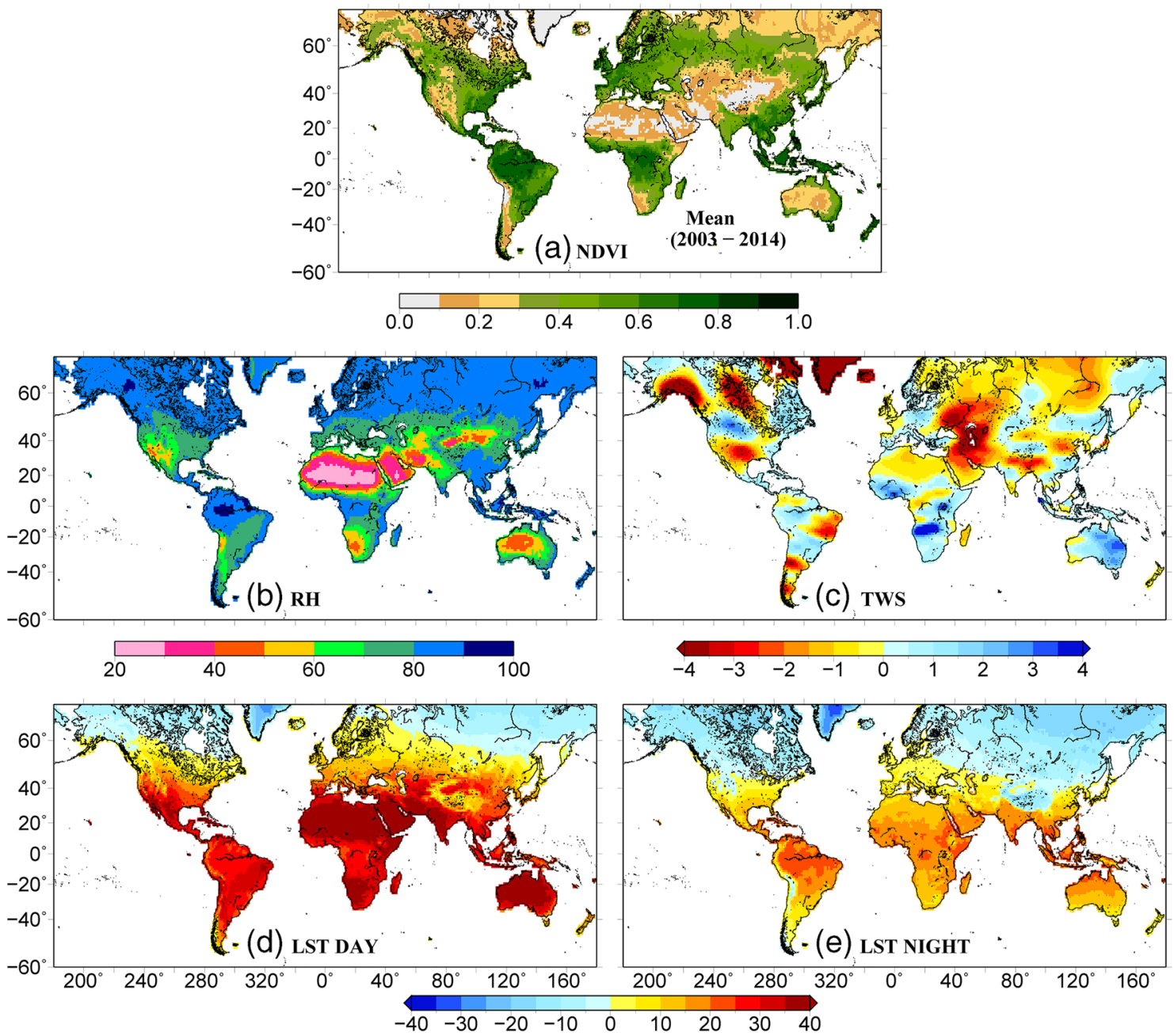

Figure 2. Annual mean climatology of NDVI, relative humidity (\%), terrestrial water storage $(\mathrm{cm})$, day and night-time LST $\left({ }^{\circ} \mathrm{C}\right)$ from $2003-2014$. LST, Land surface temperature; NDVI, Normalized Difference Vegetation Index.

find disparities in the change of NDVI in agricultural and nonagricultural areas for the selected regions. For instance, India and China were the only two regions that experienced a significant ( $\mathrm{p}$-value $<0.05$ ) increase in NDVI in nonagricultural areas (Figures $3 \mathrm{f}$ and Figure S2). Agricultural areas in the USA had a statistically significant decline in NDVI, while the decrease in NDVI in nonagricultural regions was not significant (Figure 3, Figure S2). Overall, we found a significant increase and decline in NDVI of global agricultural and nonagricultural areas that might be contributed by the changes in the hydroclimatic variables during 2003-2014. Moreover, the changes in NDVI in agricultural and nonagricultural regions were different, which highlights the need for understanding the role of hydroclimatic drivers on interannual variability of vegetation growth.

Changes in the four hydroclimatic variables (relative humidity, terrestrial water storage, day-time land surface temperature, and night-time land surface temperature) were analyzed for the 2003-2014 period (Figure 3). Relative humidity increased over the majority of the global landmass (Figure 3b). A significant (P-value $<0.05$ ) rise in relative humidity occurred in the agricultural regions of India, China, Europe, and Africa (Figure 3g). The same areas, along with Australia, also had a significant rise in relative humidity over nonagricultural regions (Figure 31). TWS, which is an indicator of water availability, had a significant (P-value $<0.05$ ) increase only in Africa. All the other regions experienced either a decline or a nonsignificant increase in TWS (Figure 3c). For example, agricultural areas in Russia, Argentina and Europe experienced 
(a) NDVI

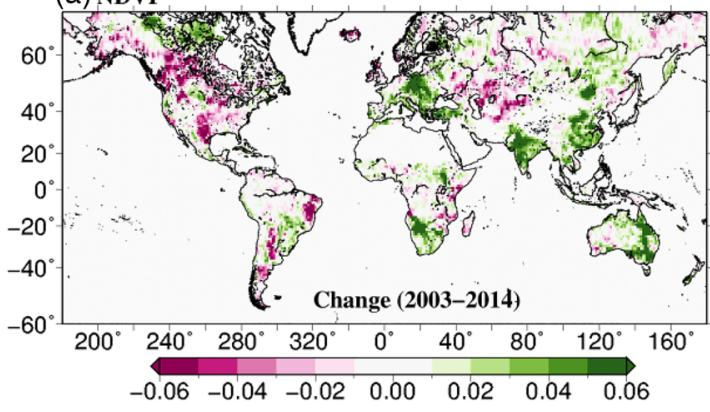

(b) RH (\%)

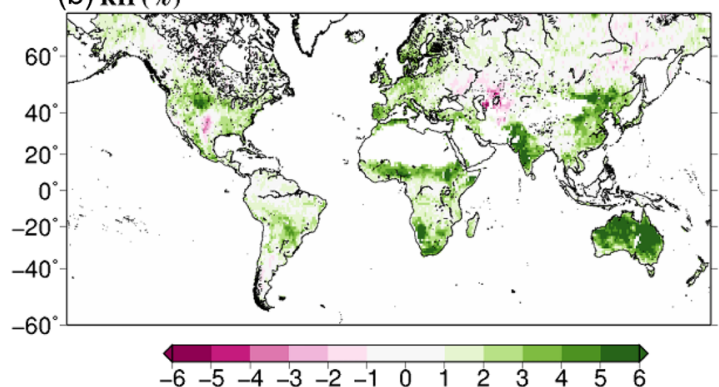

(d) LST DAY $\left({ }^{\circ} \mathrm{C}\right)$

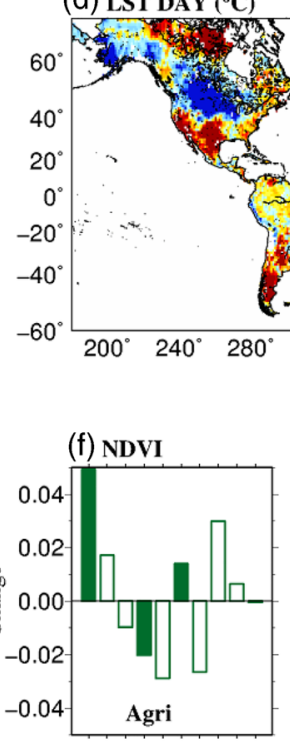

(k)
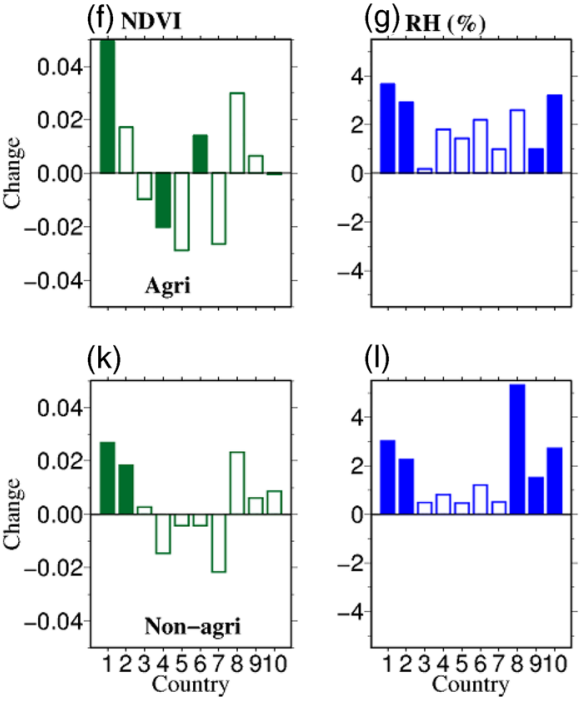

(c) TWSI (cm)

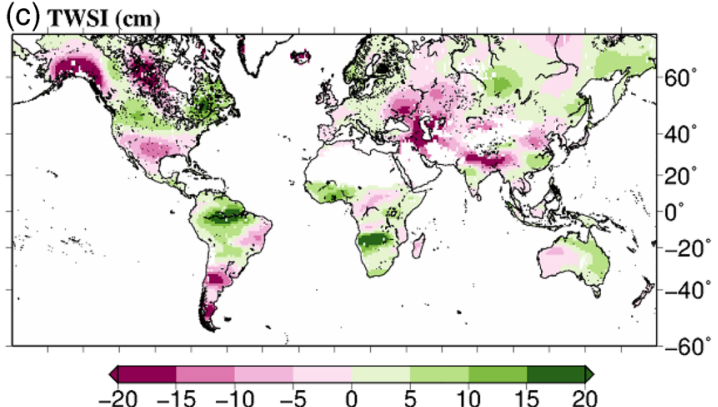

(e) LST NIGHT $\left({ }^{\circ} \mathbf{C}\right)$

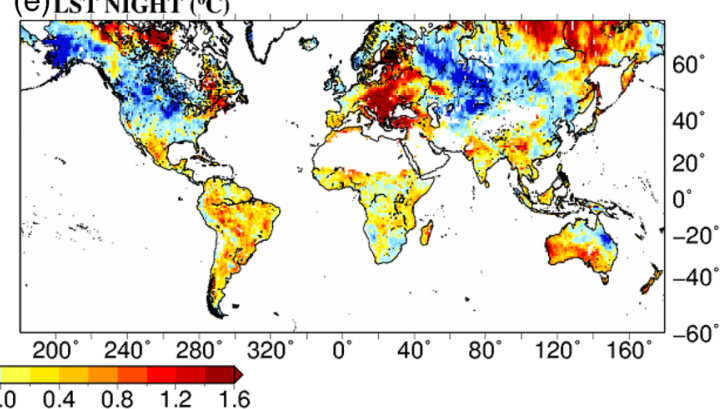

(h) TwS (cm)
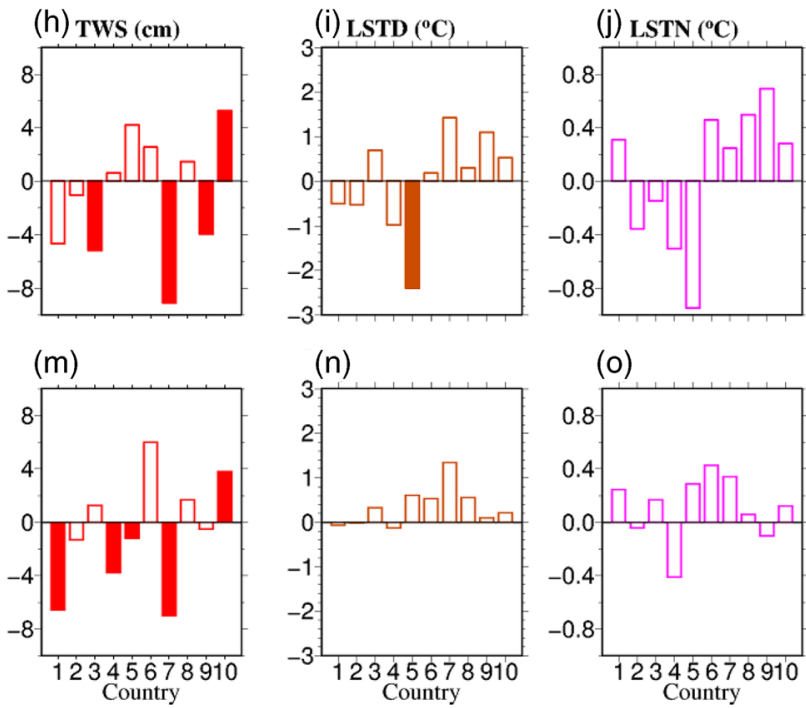

(o)

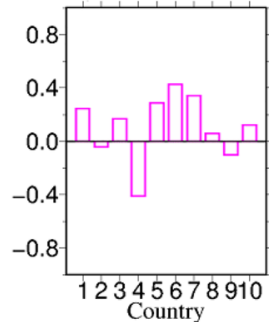

Figure 3. The change in (a) Normalized Difference Vegetation Index (NDVI), (b) relative humidity (\%), (c) terrestrial water storage (cm), (d) day-time LST $\left({ }^{\circ} \mathrm{C}\right.$ ), and (e) night-time LST from 2003 to 2014 (f)-(j) The changes in NDVI, relative humidity, terrestrial water storage, day-time land surface temperature, and night-time land surface temperature in the selected regions (1:India, 2:China, 3:Russia, 4:USA, 5:Canada, 6:Brazil, 7:Argentina, 8:Australia, 9:Europe, and 10:Africa) for agriculture ( $\mathrm{k}-\mathrm{o}$ ) Same as (f)-(j) but for Nonagricultural area. The filled bars show statistically significant changes at a 5\% significance level. Changes were estimated using nonparametric Mann-Kendall trend test and Sen's slope method. LST, Land surface temperature. 
a significant decrease in terrestrial water storage (Figures $3 \mathrm{c}$ and $3 \mathrm{~h}$ ). Moreover, a substantial decline in TWS occurred over the nonagricultural areas of India, CONUS, Canada and Argentina (Figures $3 \mathrm{c}$ and $3 \mathrm{~m}$ ).

Similar to relative humidity and TWS, considerable changes were found in land surface temperatures during the 2003-2014 period. A decline in day-time LST was found in the agricultural areas of India, China, CONUS, and Canada. At the same time, the other regions showed a rise in day-time LST (Figures 3d and 3i). Only Canada experienced a significant ( $p$-value $<0.05$ ) decline of about $1^{\circ} \mathrm{C}$ in day-time land surface temperature during the 2003-2014 period (Figure 3d). A majority of the nonagricultural areas experienced an increase in day-time land surface temperature during 2003-2014 (Figure 3n). Similarly, night-time LST (night-time land surface temperature) increased in the agricultural areas of India, Brazil, Argentina, Australia, Europe and Africa. In contrast, a decline in night-time land surface temperature was found in China, Russia, CONUS and Canada (Figures $3 e$ and $3 j$ ). Our results show that night-time land surface temperature has increased ( $p$-value $>0.05$ ) in the majority of the nonagricultural areas (Figure 3o). Overall, we find that changes in both NDVI and hydroclimatic variables were different in agricultural and nonagricultural areas.

We find that NDVI significantly increased in India and Brazil for agricultural areas. India and China were the only two countries that experienced a significant increase in NDVI in the nonagricultural ecosystems. Increase in NDVI in China is notably occurred in primarily forested areas, while in India, agricultural areas were the primary locations of increased NDVI. In both the countries, human land use management dominated by the use of fertilizers and irrigation played an essential role in the greening of vegetation in agricultural areas (Chen et al., 2019; Piao et al., 2020). In contrast, NDVI significantly declined in agricultural regions of the CONUS with the most notable reductions in the south-central part of the country (e.g., Texas). This decline in NDVI can be partly attributed to recurrent droughts that occurred in this part of the CONUS during the study period (Kogan et al., 2013; Long et al., 2013; Vicente-Serrano et al., 2013)

Our results show an increase in global-scale relative humidity during the 2003-2014 period, which is associated with the rise in atmospheric water vapor in response to anthropogenic greenhouse gases emissions (Schneider et al., 2010; Willett et al., 2007). The decline in TWS in India, CONUS, and South America is consistent with human activities (groundwater abstraction) and natural causes (e.g., persistent droughts, Asoka et al., 2017; Rodell et al., 2009, 2018). Cooling in day-time land surface temperature in India, China, and the northern part of CONUS can be attributed to irrigation and agricultural intensification (Bonfils \& Lobell, 2007; Han \& Yang, 2013; Mueller et al., 2015). Moreover, afforestation in China has also contributed to a reduction in temperature (Mildrexler et al., 2011; Peng et al., 2014). On the other hand, climate warming has caused warming in day-time and night-time land surface temperatures over Europe (Seneviratne et al., 2006).

\subsection{The Linkage Between Vegetation Growth and Hydroclimatic Variables}

Standardized anomalies of NDVI and the hydroclimatic variables were used to examine the role of hydroclimatic variables on vegetation growth. First, we estimated Pearson's correlation between detrended standardized anomalies of NDVI and hydroclimatic variables. We estimated correlations for selected 10 regions to examine the variation in the relationship between NDVI and the hydroclimatic variables (Figure 4, Tables S3 \& S4). We also estimated the median correlation between standardized (and detrended) NDVI (agricultural and nonagricultural) and the four hydroclimatic variables for each thermal zone (Table S5, Figure S1). A positive relationship (correlation $\geq 0.4$ ) between NDVI and relative humidity was found for most regions except China and Canada (Figures 4a, 4e, and 4f, Tables S3 \& S4). The median correlation for the thermal zones showed a positive correlation $(r \sim 0.4)$ between NDVI and relative humidity in the tropics and subtropics regions (Table S5). Temperate, boreal and arctic regions exhibited a negative correlation between vegetation growth and relative humidity (Table S5).

Terrestrial water storage (TWS) is positively associated with NDVI in most of the vegetated areas (Velicogna et al., 2015; Yang et al., 2014) except in the northern latitudes, which is an energy-limited environment (Figures 3a and 3b). A significant $(P$-value $<0.05)$ positive relationship between NDVI and terrestrial water storage in agricultural areas was found for all the regions except China (Figure 4e). The weaker relationship between NDVI and terrestrial water storage shows that the greening in China's agricultural areas is not strongly associated with water availability but somewhat controlled by the human land management 
(a) NDVI-RH

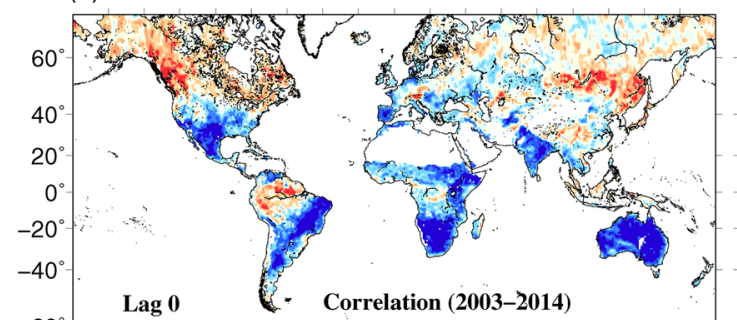

$-60^{\circ} \frac{\text { Lag } 0}{\text { (c) NDVI-LSTD }}$

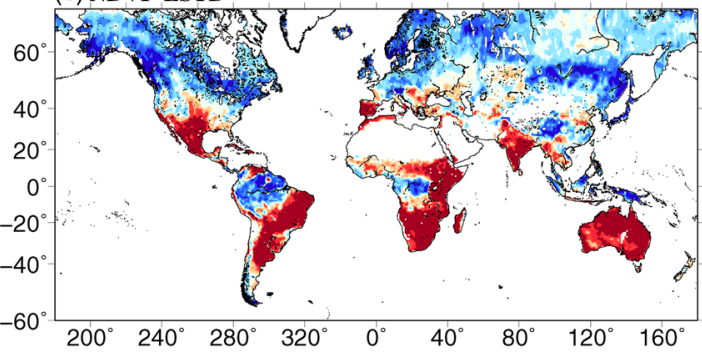

(e) Agriculture (b) NDVI- TWSI
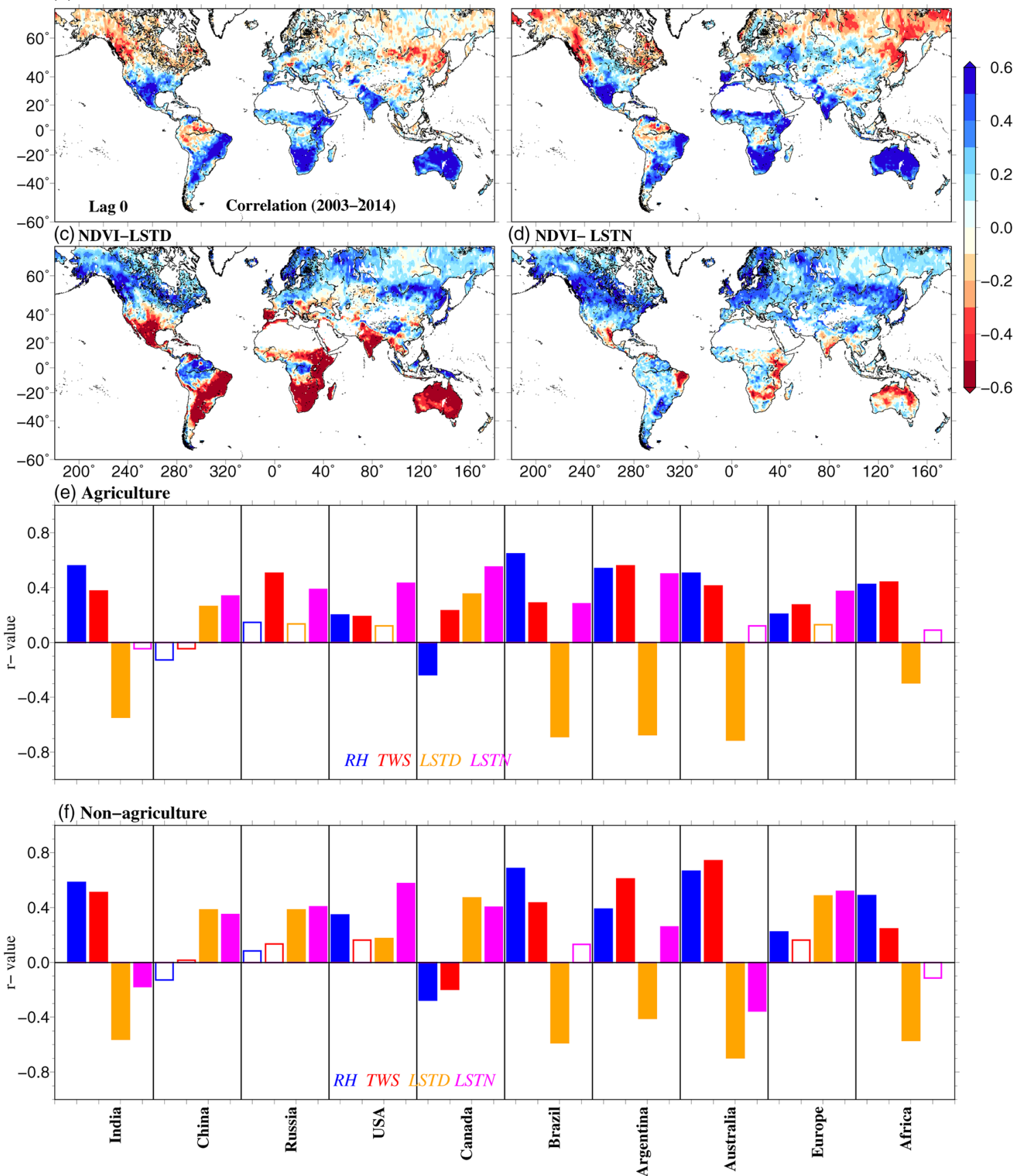

Figure 4. Correlation between three months mean standardized NDVI and (a) relative humidity (RH), (b) terrestrial water storage (TWS), (c) day time land surface temperature (LSTD), and (d) night-time land surface temperature (LSTN) for the 2003-2014 period. 3-Month standardized detrended anomalies of NDVI, relative humidity, terrestrial water storage, day-time land surface temperature, and night-time land surface temperature from 2003 to 2014 period for correlation analysis. The correlation (r) of NDVI with relative humidity, terrestrial water storage, day-time land surface temperature, and night-time land surface temperature for (e) agriculture and (f) nonagricultural area for the selected region. Filled bars show a statistically significant correlation at 5\% confidence level. NDVI, Normalized Difference Vegetation Index.

practices (Chen et al., 2019; Piao et al., 2020). NDVI in India, Brazil, Argentina, Australia, and Africa is positively correlated with TWS in nonagricultural regions, which indicates the role of water availability on vegetation growth. In contrast, the TWS is negatively correlated with vegetation growth in energy-limited, higher latitude areas of Canada (Geruo et al., 2015, Figure 4). Moreover, vegetation growth in the majority of tropics, subtropics, and temperate regions is positively associated with TWS. In comparison, 
energy-limited regions (boreal and Arctic) show a negative relationship between vegetation growth and terrestrial water storage (Table S5).

NDVI in the agricultural ecosystems of India, Brazil, Argentina, and Africa show a significant (p-value $<0.05)$ negative relationship $(r<-0.5)$ with day-time land surface temperature. On the other hand, a significant positive relationship $(r \sim 0.3)$ between NDVI and day-time land surface temperature was observed in western China and Canada (Figure 4e). Vegetation in nonagricultural areas also follows a similar relationship between NDVI and day-time land surface temperature across the 10 regions (Figure 4f). Moreover, a strong negative relationship between detrended and standardized day-time land surface temperature and NDVI was found over most of the tropics and subtropics warm/moderately cold regions. In contrast, vegetation in northern latitudes $\left(>40^{\circ} \mathrm{N}\right)$ and cold mountainous regions had a positive relationship between NDVI and day-time land surface temperature (Figure 4c). These results further confirm that vegetation in the energy-limited regions is positively correlated with day-time LST (Figure 4c) while negatively associated with terrestrial water storage (Figure $4 b$ ).

A positive relationship between standardized NDVI and night-time land surface temperature was found in the majority of the cold and higher-latitude regions (Figure 4d). However, in the lower-latitude tropical regions, both negative and positive relationships can be observed between NDVI and night-time land surface temperature (Sun et al., 2013, Figure 4d). For instance, the tropical areas of South America and Africa experience both negative and positive relationships between NDVI and night-time land surface temperature. Vegetation in the agricultural areas shows a positive correlation between NDVI and night-time land surface temperature except in India (Figure 4e). Vegetation in nonagricultural areas is positively correlated with night-time land surface temperature except for India, Australia, and Africa (Figure 4f). In all the thermal zones, vegetation growth is positively correlated with night-time land surface temperature (Table S5). We also evaluated the relationship between NDVI and day-time land surface temperature and night-time land surface temperature from MODIS Terra (overpass time 10.30 a.m. and 10.30 p.m., Figure S3a-S3d), which shows a similar relationship that was obtained using the data from MODIS Aqua (1.30 p.m. and 1.30 a.m.) (Figures 4a-4d).

\subsection{Relative Contribution of Hydroclimatic Variables in Vegetation Growth}

After evaluating the relationship between vegetation growth and the hydroclimatic variables, the relative contribution of relative humidity, terrestrial water storage, day-time land surface temperature, and nighttime land surface temperature on vegetation (NDVI) growth was quantified using detrended and standardized time series of variables for the 2003-2014 period (Figure 5). A lower contribution from relative humidity on vegetation growth was found in comparison to the other three hydroclimatic variables (Table S7, Figure 5a). The relative contribution of relative humidity was the highest (among four hydroclimatic variables) in only $9 \%$ of the total global agricultural and nonagricultural areas (Figures 5a and $5 \mathrm{~g}$ ). The relative contribution of TWS on vegetation growth was the highest in $23 \%$ of the total vegetated area (Figures $5 \mathrm{~b}$ and $5 \mathrm{~g})$. The relative contribution of day-time and night-time land surface temperatures occurred over a much larger area than both relative humidity and TWS. The day-time land surface temperature was a significant contributor to interannual variability in vegetation growth in $37 \%$ of the total vegetated areas, followed by night-time land surface temperature that is a dominant contributor in $29 \%$ of the entire vegetated areas. Therefore, both day-time and night-time land surface temperatures are the major contributors to vegetation growth in the two-third (66\%) of vegetated areas globally (Figures 5c, 5d, and 5g). The day-time land surface temperature is the primary contributor in the tropical and subtropical regions. In contrast, night-time land surface temperature controlled the vegetation growth in the higher latitudes (Figure 5).

The contribution of relative humidity (15\%) and day-time land surface temperature (14\%) in vegetation growth for agricultural areas in India was found to be comparable with a total explained variance of 35\% (Figure 5e, Table S7). In China, the four hydroclimatic variables explained the least variance of vegetation growth for both agricultural (13\%) and nonagricultural areas (17\%, Figures 5e and 5f). The lower contribution from the hydroclimatic variables on interannual variability of the vegetation growth in China can be attributed to human influence and land management (Chen et al., 2019; Piao et al., 2020). TWS was the major contributor (15\%) followed by night-time land surface temperature (14\%) in vegetation growth in the agricultural regions in Russia with a total explained variance of 35\% (Table S7, Figures 5e and 5f). 


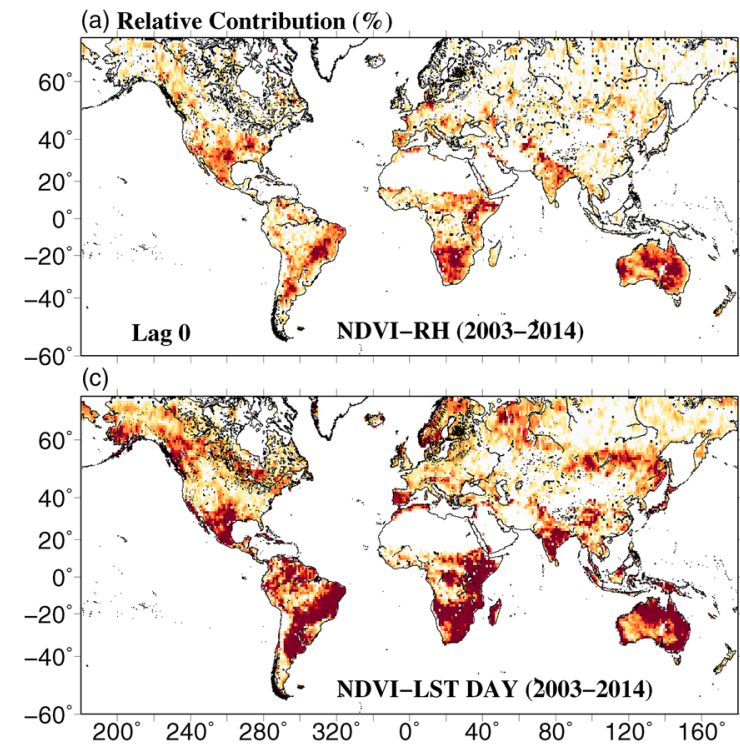

(b)
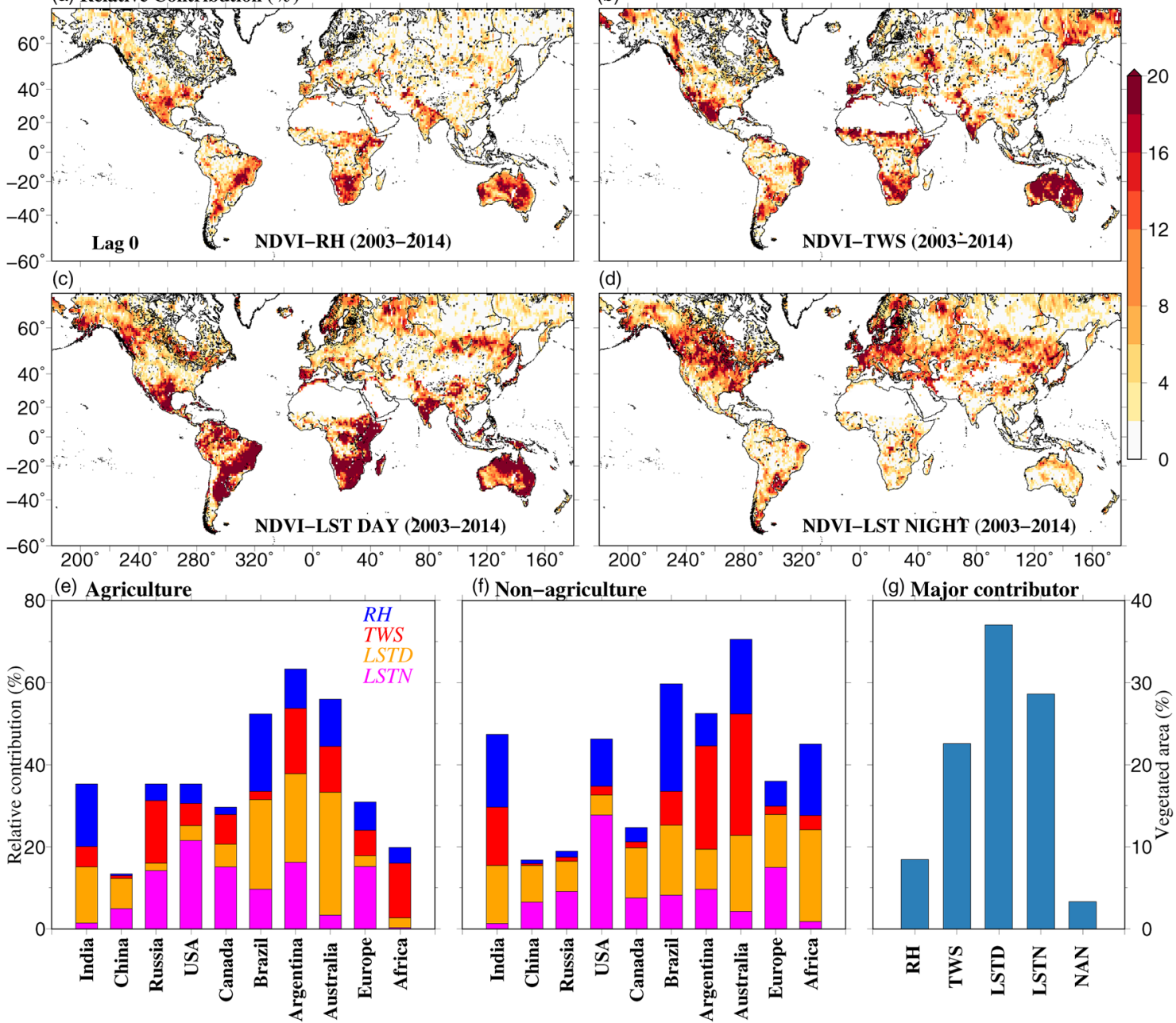

(g) Major contributor

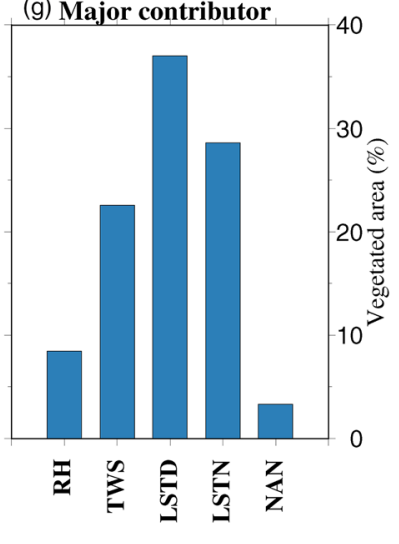

Figure 5. (a-d) Relative importance of (\% of R2) of relative humidity (RH), terrestrial water storage (TWS), day-time land surface temperature (LSTD), and night-time land surface temperature (LSTN) to detect the changes in NDVI anomaly. (e) The relative contribution of relative humidity, terrestrial water storage, day-time land surface temperature, and night-time land surface temperature to NDVI in the selected region for agriculture. (f) same as E but for the nonagricultural area. (g) The percentage of the global vegetated area where the major contributor to NDVI anomaly is relative humidity, terrestrial water storage, day-time land surface temperature or night-time land surface temperature. The NAN represents the percentage of vegetated area with no sufficient number of data points. NDVI, Normalized Difference Vegetation Index.

Night-time land surface temperature contributes the maximum in the agricultural areas of the USA (22\%), Canada (15\%) and Europe (15\%) with a total explained variance of 35\%, 30\%, and 31\%, respectively. On the other hand, the day-time land surface temperature is a significant contributor to vegetation growth in Brazil (22\%), Argentina (22\%), and Australia (30\%). Our results show that among the hydroclimatic variables, day and night-time land surface temperatures explain the highest amount of variance. However, this highest variance is still less than $60 \%$, which means that about $40 \%$ of the total variance is explained by other factors (e.g., $\mathrm{CO}_{2}$ fertilization and human land management) that are not considered in our analysis.

All four hydroclimatic variables affect vegetation growth in the agricultural and nonagricultural regions. For instance, relative humidity is an important factor that governs the plant growth rate and controls evaporation (AghaKouchak et al., 2015; Tibbitts, 1979). The relative humidity is linked to precipitation and can be used as an indicator for early detection of drought (Farahmand et al., 2015). Day and night-time temperatures play a vital role in vegetation growth, and the influence of temperature can vary with plant species and the agro-climatic settings. Day time land surface temperature directly influences the plant photosynthetic activity, whereas both day and night time temperatures affect plant respiration (Peng et al., 2013). The increase in day time temperature in the cold regions (or energy-limited regions) can improve the 
photosynthetic activity and extend the growing season (Menzel et al., 2006; Peng et al., 2013). However, in the water-limited regions, rise in day time temperature can reduce the vegetation growth (Alfaro et al., 2006). On the other hand, a rise in night-time temperature can result in higher vegetation respiration and reduced biomass accumulation rate (Hatfield \& Prueger, 2015). Overall, we find that the relative contribution of the hydroclimatic variables on the interannual variability of vegetation growth can vary in the agricultural and nonagricultural regions. Our results show that the total explained variance by the four hydroclimatic variables is higher for the nonagricultural regions in comparison to agricultural regions for the majority of the 10 selected countries. Day and night-time LST was the dominant contributor among the four hydroclimatic variables of vegetation growth in about two-thirds of the global vegetated landmass. We did not consider the role of agricultural management and policies in different countries that may affect vegetation growth, which is a limitation of our analysis as our main objective was to estimate the relative contribution of hydroclimatic variables on vegetation growth. Data availability related to agricultural policies and land use management can help in identifying the role of human land management on vegetation growth in the agricultural areas of different countries in future.

\subsection{Lagged Response of Vegetation to Hydroclimatic Factors}

Vegetation response and growth can have a time-lag effect with the hydroclimatic variables (Asoka \& Mishra, 2015; Farahmand \& AghaKouchak, 2015; Funk \& Brown, 2006; Wu et al., 2015). Time lag correlation (ranging from 0 to 3 months) between NDVI and the four hydroclimatic variables for the 2003-2014 period (Figure 6). A 3-month detrended, standardized NDVI and hydroclimatic variables to estimate the lag correlation. For the majority of the regions, the correlation between NDVI and hydroclimatic variables is the highest at zero lag for both agricultural and nonagricultural ecosystems (Figure 6). Relative humidity, TWS, day-time land surface temperature and night-time land surface temperature showed the highest correlation at a 1-month lag in $26 \%, 10 \%, 22 \%$ and $24 \%$ of the global agricultural areas, respectively (Figure 6e). Both relative humidity and the day-time land surface temperature had a higher correlation with NDVI at a 1-month lag in Australia and parts of western and southern USA (Figures 6a and 6c). Similarly, relative humidity, terrestrial water storage, day-time land surface temperature, and night-time land surface temperature showed the highest correlation at a 1-month lag in $23 \%, 7 \%, 22 \%$, and $19 \%$ of global nonagricultural ecosystems (Figure 6f). The relationship between NDVI and hydroclimatic variables is weaker for the majority of the vegetated regions at the two- and 3-months lag intervals (Figure 6). The lagged relationship between NDVI and day-time land surface temperature and night-time land surface temperature can be used to predict the vegetation anomalies in agricultural and nonagricultural ecosystems (Asoka \& Mishra, 2015; Funk \& Brown, 2006).

\subsection{Role of $\mathrm{CO}_{2}$ on Vegetation Growth}

We estimated correlation between three months standardized NDVI against the standardized precipitation (SPI), maximum and minimum temperature indices during 2003-2014 period (Figure 7). Besides, we estimated the relationship between NDVI and $\mathrm{CO}_{2}$ on vegetation growth during the same (2003-2014) period. Our results show that the relationship between SPI and terrestrial water storage is consistent (Figures 4 and 7); however, terrestrial water storage has a stronger relationship with vegetation growth in both agricultural and nonagricultural regions. This more robust relationship between terrestrial water storage with vegetation can be attributed to high persistence (Asoka \& Mishra, 2020; Xie et al., 2019). Moreover, the relationship between maximum and minimum air temperatures with vegetation is also consistent with our results based on the day and night-time land surface temperature (Figures 4 and 7). However, day-time land surface temperature shows a stronger relationship with vegetation growth in comparison to maximum air temperature. Overall, we find that terrestrial water storage and day-time land surface temperature can be better predictors than precipitation and maximum air temperature of vegetation growth (Figures 4 and 7).

To further confirm the role of $\mathrm{CO}_{2}$ on vegetation growth, we used simulations from the Land Use Model Intercomparison Project (LUMIP). We compared the mean annual leaf area index (LAI, without removing trends) from the three scenarios: LAI-HIST, LAI-CCLIM, and LAI-CCO $\mathrm{C}_{2}$ to examine the climate and $\mathrm{CO}_{2}$ contributions on vegetation growth during 2003-2013. The LAI-HIST scenario includes the effect of all forcing (natural + anthropogenic). The LAI-CCLIM scenario shows the effect of constant climate but varying 
(a) RH

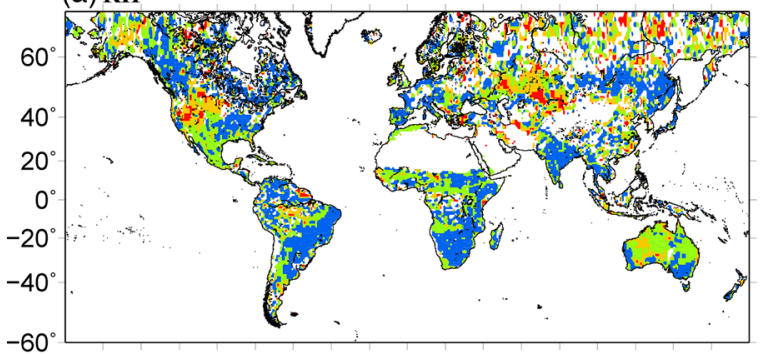

(c) LSTD

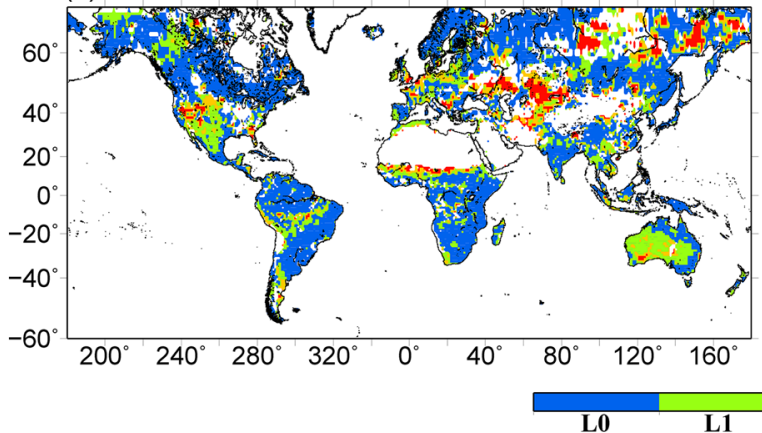

(e) Agriculture

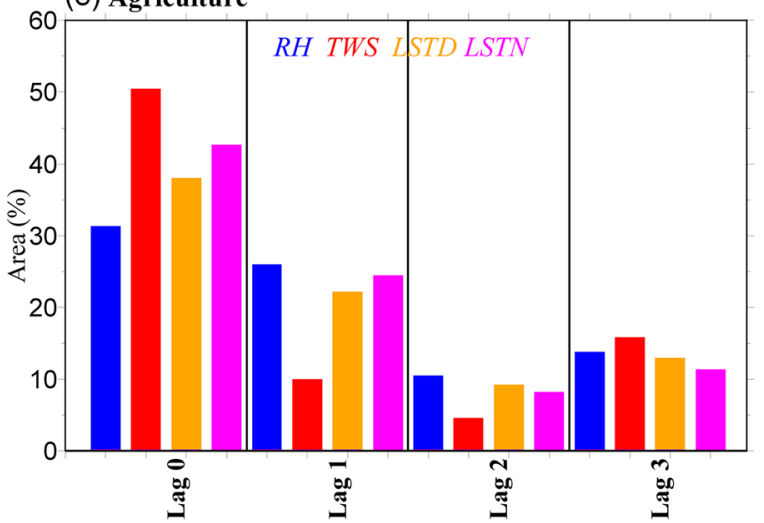

(b) TWS

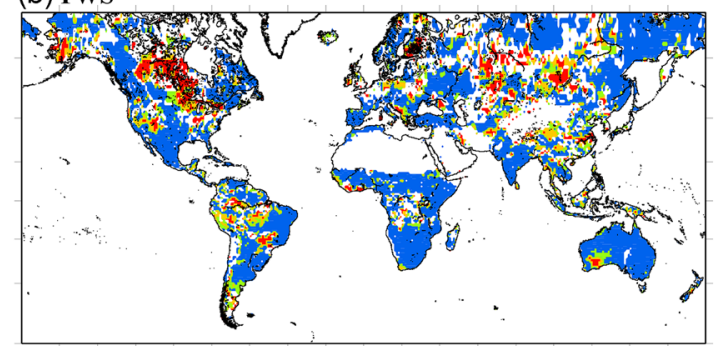

(d) LSTN

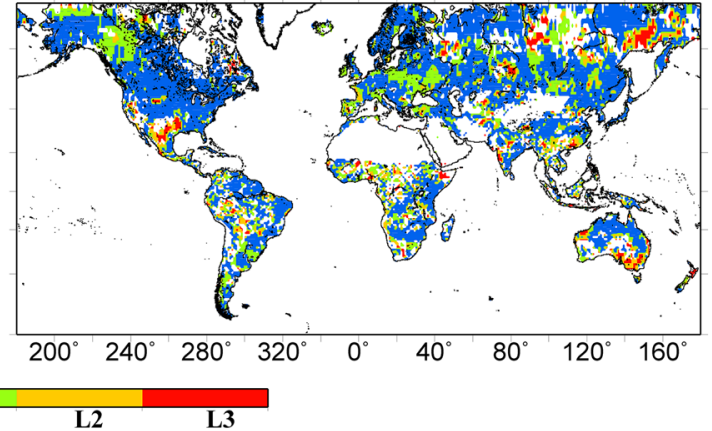

(f) Non-agriculture

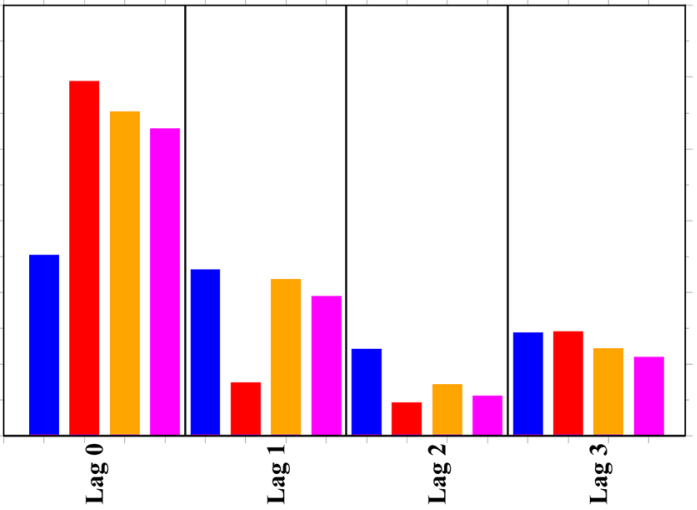

Figure 6. The lagged (0-3 months) correlation analysis of NDVI with relative humidity (RH), terrestrial water storage (TWS), day-time land surface temperature (LSTD), and night-time land surface temperature (LSTN) (a-d) The best lag for each grid to detect NDVI anomaly (at $90 \%$ confidence level) using relative humidity, terrestrial water storage, day-time land surface temperature, and night-time land surface temperature, respectively. Area (\%) under maximum lagged correlation of NDVI with the other hydroclimatic factors. NDVI, Normalized Difference Vegetation Index.

$\mathrm{CO}_{2}$ concentration. On the other hand, the $\mathrm{LAI}-\mathrm{CCO}_{2}$ shows the constant $\mathrm{CO}_{2}$ concentration and varying climate condition. The climatology of LAI from the three LUMIP experiments during the 2003-2013 period shows a similar pattern in the majority of global vegetated areas (Figures 8a-8c). However, a relatively high LAI was observed in the Amazon region and part of Africa under LAI-HIST and LAI-CCLIM simulations compared to the LAI- $\mathrm{CCO}_{2}$ simulations. Also, changes in mean annual LAI over Amazon and northern latitudes are more remarkable in LAI-HIST and LAI-CCLIM in comparison to LAI-CCO 2 during 2003-2014 (Figures 8d-8f). We find that changes in mean annual LAI in LAI-HIST and LAI-CCLIM are similar (Figures $8 \mathrm{~d}$ and $8 \mathrm{e}$ ), which indicates that the varying $\mathrm{CO}_{2}$ concentration has a larger control on the changes in LAI-HIST. On the other hand, the contribution of climate on the change in LAI in the LAI-HIST scenario is relatively lesser (Figure 8f). Since we did not remove the trends from mean annual LAI, a higher contribution of $\mathrm{CO}_{2}$ on the changes in LAI is visible. To further examine the influence of the length of record on the contribution of climate and $\mathrm{CO}_{2}$ concentration on the changes in LAI, we used the simulations for the three scenarios (LAI-HIST, LAI-CCLIM, and LAI-CCO ${ }_{2}$ ) for 1950-2015 period from the LUMIP. We find that $\mathrm{CO}_{2}$ concentration contributes more than climate to the changes in LAI in the LAI-HIST scenario. For instance, 


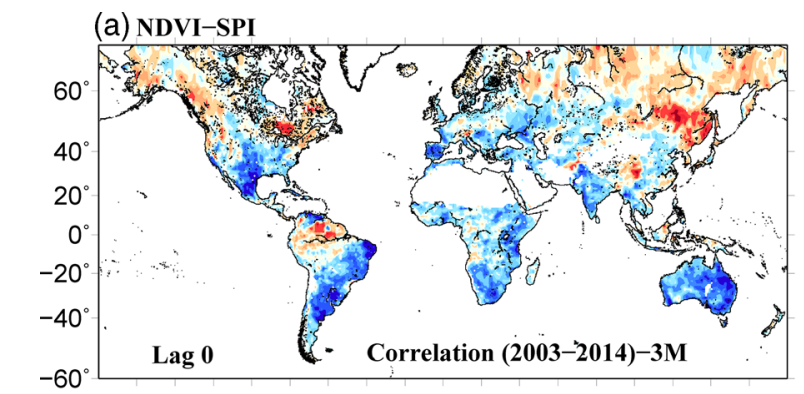

(b) $\mathrm{NDVI}-\mathrm{CO}_{2}$
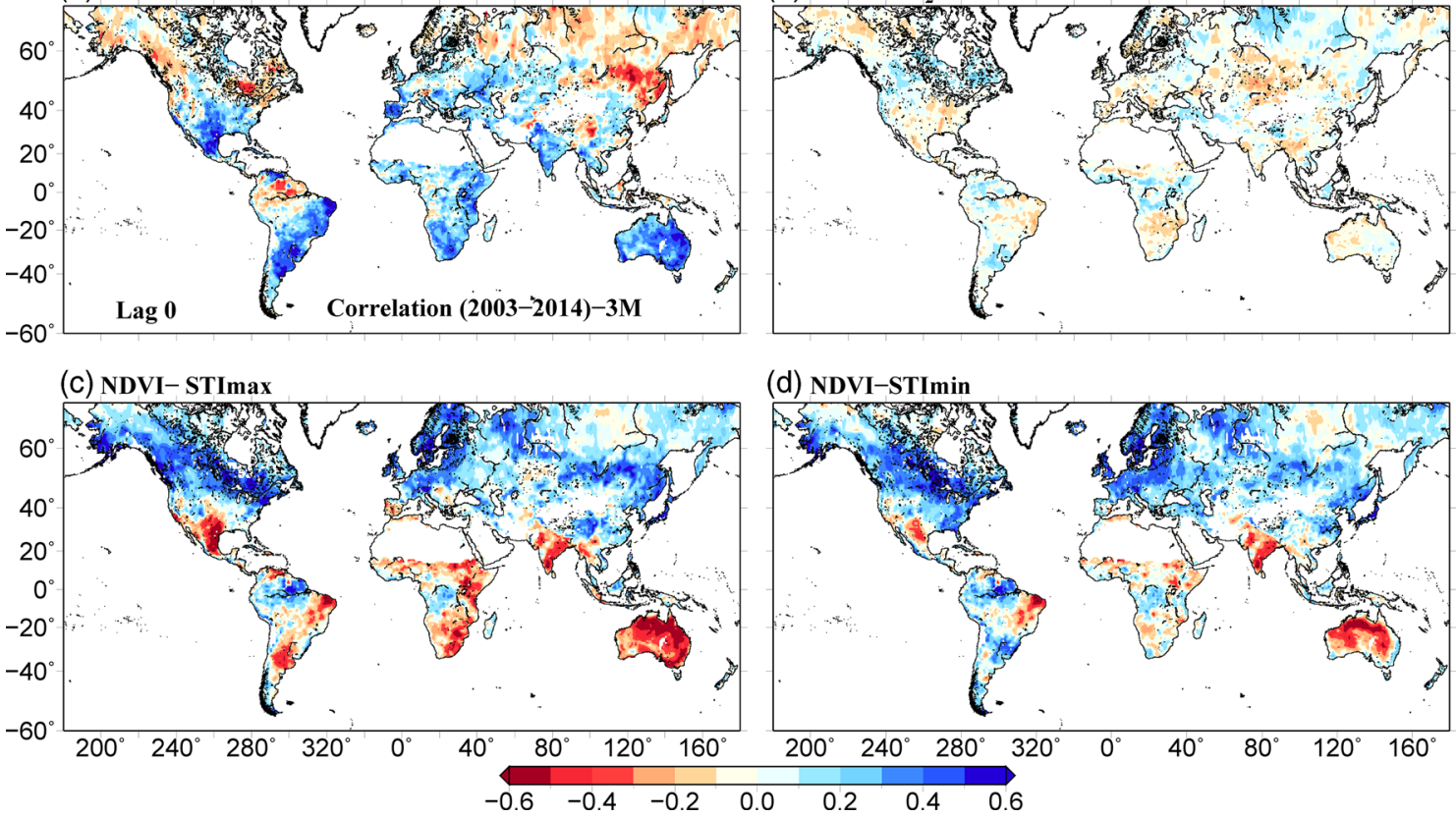

Figure 7. Correlation between three months mean standardized NDVI and (a) standardized precipitation index (SPI), (b) $\mathrm{CO}_{2}$ growth rate from Mauna Loa, (c) maximum temperature and minimum temperature for the period 2003-2014. 3-Month standardized detrended anomalies of precipitation, $\mathrm{CO}_{2}$, maximum and minimum temperature were used for the correlation analysis. NDVI, Normalized Difference Vegetation Index.

changes in LAI in the LAI-HIST and LAI-CCLIM are similar, which indicates the vital role of $\mathrm{CO}_{2}$ concentration on the vegetation growth (Figure 9). Since we removed the trend from NDVI and $\mathrm{CO}_{2}$ concentration in our analysis, a weaker relationship between NDVI and $\mathrm{CO}_{2}$ concentration was observed in comparison to the other hydroclimatic variables (Figures 4 and 7).

\section{Discussion and Conclusions}

Changes in NDVI and the four hydroclimatic variables in the global agricultural and nonagricultural areas were evaluated during the 2003-2014 period in this study. Our analysis showed that the day and night time land surface temperatures have major control on the vegetation growth in the agricultural and nonagricultural areas. Previous studies also reported the dominant role of air temperature on vegetation growth (Seddon et al., 2016; Wu et al., 2015; Zhao et al., 2018; Zhu et al., 2016). In addition, $\mathrm{CO}_{2}$ fertilization due to anthropogenic greenhouse gas emissions contributed significantly to the vegetation growth during the last few decades. For instance, Nemani et al. (2003) reported a rise of $6 \%$ in the net primary productivity during 1982-1999, primarily due to climate change. Similarly, Zhao et al. (2018) found a large contribution from greenhouse gas emissions on vegetation growth during $1982-2013 . \mathrm{CO}_{2}$ fertilization has been a major driver of the observed greening trends during 1982-2013 ( $\mathrm{Zhu}$ et al., 2016). Apart from the role of $\mathrm{CO}_{2}$, most of the previous studies considered precipitation and maximum and minimum temperatures to examine the relationship with vegetation growth (Zhao et al., 2018; Zhu et al., 2016).

We observed a relatively weaker relationship (in comparison to the other hydroclimatic variables) between 3-month standardized NDVI and $\mathrm{CO}_{2}$ during the 2003-2014 period (Figure 7b). This weaker relationship can be due to a relatively shorter period used in our analysis (Los, 2013; Thompson et al., 1996). Previous studies (Zhao et al., 2018; Zhu et al., 2016) that showed the higher contribution of $\mathrm{CO}_{2}$ on observed vegetation growth trends based on the long-term analysis (1982-2013). The other reason behind the weaker relationship between $\mathrm{CO}_{2}$ concentration and vegetation growth can be associated with the detrending of NDVI and hydroclimatic variables used in our analysis. For instance, we used 3-month standardized and detrended NDVI and hydroclimatic variables. The removal of trends can result in the weaker relationship 
(a) LAI-HIST

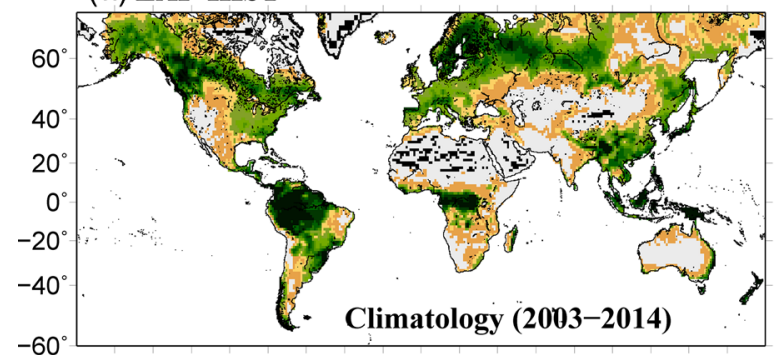

(b) LAI-CCLIM

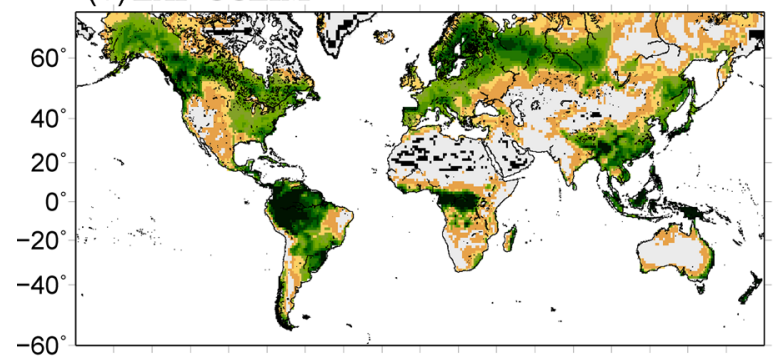

(c) $\mathrm{LAI}-\mathrm{CCO}_{2}$

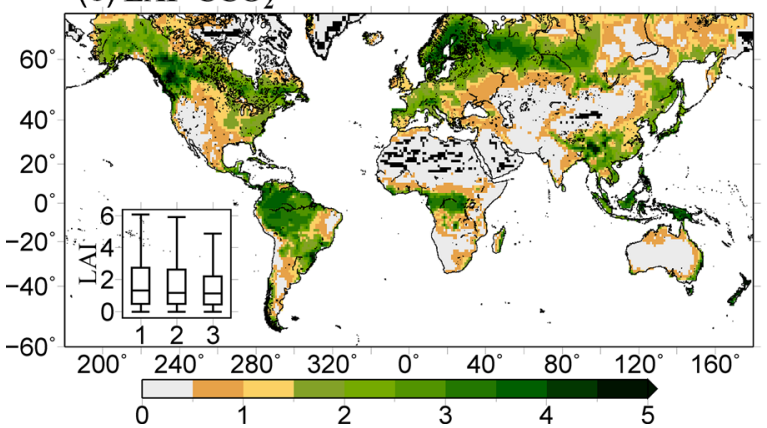

(d) LAI-HIST

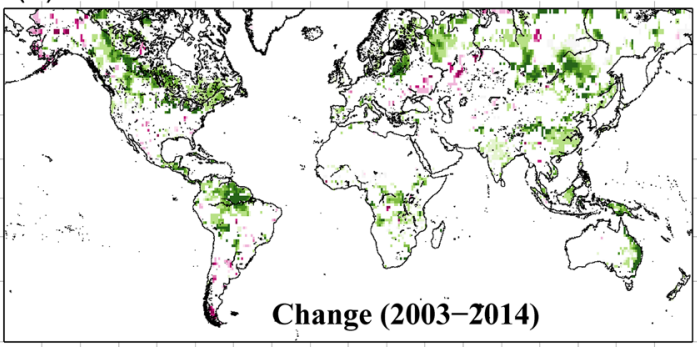

(e) LAI-CCLIM

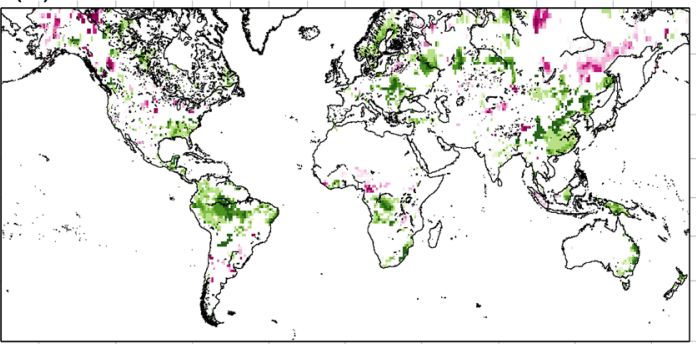

(f) $\mathrm{LAI}-\mathrm{CCO}_{2}$

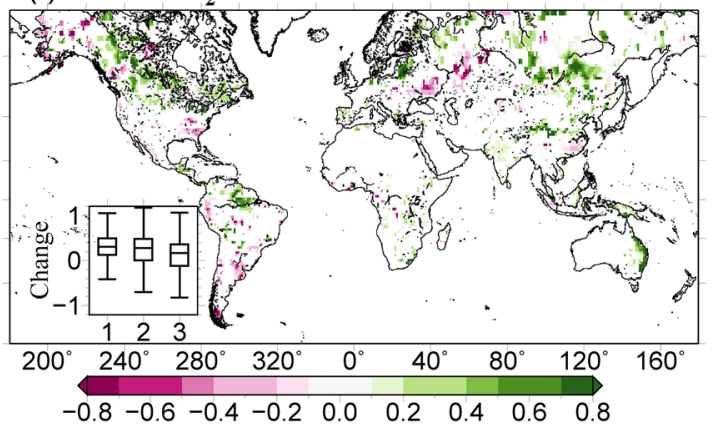

Figure 8. The climatology and change of Leaf Area Index (LAI) from LS3MIP and LUMIP experiments during 2003-2014. (a)-(c) The climatology of (a) historic LAI (LAI-HIST), LAI simulated under (b) varying $\mathrm{CO}_{2}$ (LAI-CCLIM), and (c) under constant $\mathrm{CO}_{2}\left(\mathrm{LAI}_{-}-\mathrm{CCO}_{2}\right.$ ) during 2003-2014. The box plot in the inset of (c) shows the global summary of climatology for LAI-HIST (1), LAI-CCLIM(2), and LAI-CCO ${ }_{2}$ (3). (d)-(f) The change (significant at 95\%) of (a) LAIHIST, (b) LAI-CCLIM and (c) LAI-CCO 2 during 2003-2014. The box plot in the inset of (f) shows the global summary of the change (significant at 95\%) for LAI-HIST (1), LAI-CCLIM(2), and LAI-CCO 2 (3) during 2003-2014.

between NDVI and $\mathrm{CO}_{2}$ concentration. We find that $\mathrm{CO}_{2}$ fertilization has a major influence on the increase in LAI during the short-term as well as long-term as shown by the LUMIP simulations.

In this study, satellite-based observations of the four hydroclimatic variables (relative humidity, TWS, daytime land surface temperature, and nigh-time land surface temperature) were used to quantify their relative contribution on the vegetation growth in the agricultural and nonagricultural regions during the 2003-2014 period. The role of $\mathrm{CO}_{2}$ on the vegetation growth was evaluated using the station-based observations and simulations from the LS3MIP and LUMIP experiment, which is part of the CMIP6. Based on our finding, we conclude the following:

- NDVI has significantly increased in agricultural dominated regions of India and Brazil during the 20032014 period. A considerable decline in NDVI over agricultural areas was observed in the USA. In contrast, India and China experienced a significant increase in NDVI in the nonagricultural areas during the same period

- A significant rise in relative humidity occurred in the agricultural regions of India, China, Europe, and Africa. Agricultural areas in Russia, Argentina, and Europe experienced a significant decrease in terrestrial water storage. Moreover, a substantial decline in terrestrial water storage occurred over the nonagricultural areas of India, USA, Canada, and Argentina. A decline in day-time LST was found in the 
(a) LAI-HIST

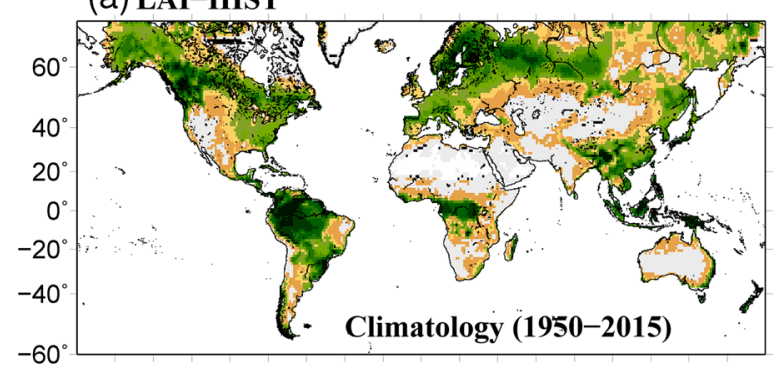

(b) LAI-CCLIM

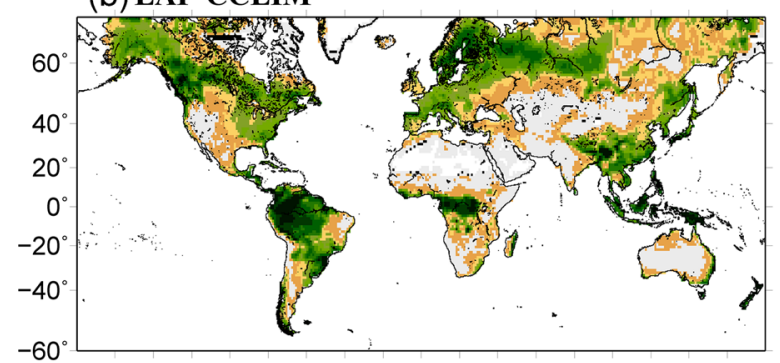

$-60^{\circ}$ (c) $\mathbf{L A I}-\mathrm{CCO}_{2}$

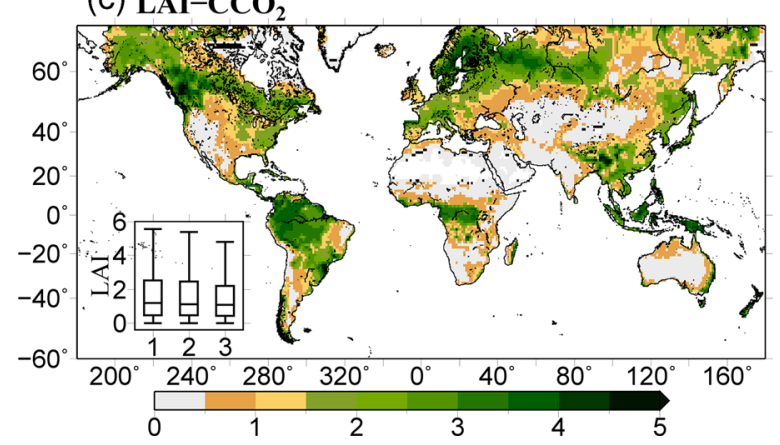

(d) LAI-HIST

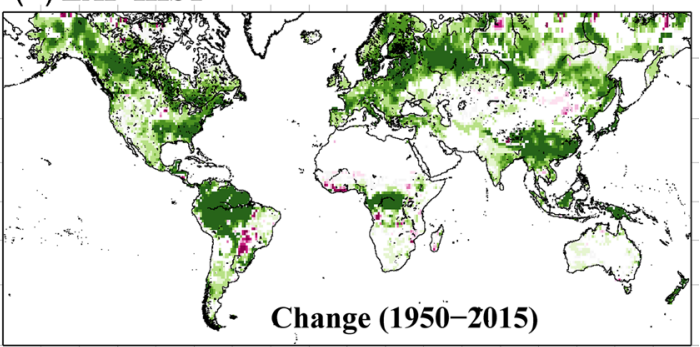

(e) LAI-CCLIM

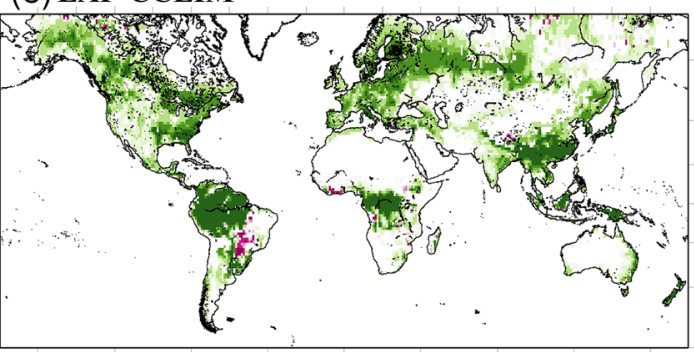

(f) $\mathrm{LAI}-\mathrm{CCO}_{2}$

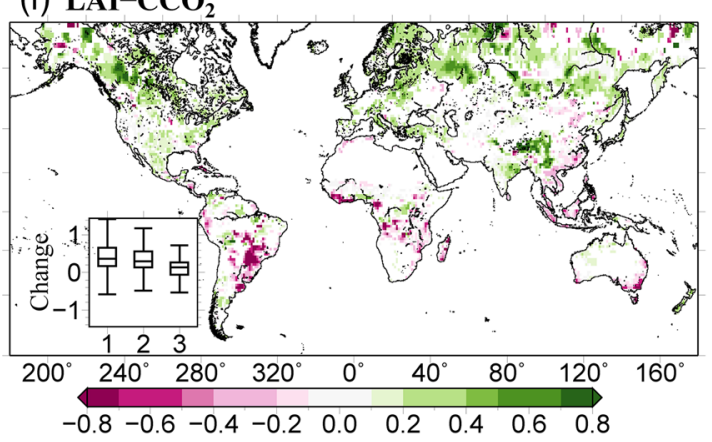

Figure 9. Same as Figure 8, but for the period 1950-2015. The climatology and change of Leaf Area Index (LAI) from LUMIP experiments during1950-2015. (a)-(c) The climatology of (a) historic LAI (LAI-HIST), LAI simulated under (b) varying $\mathrm{CO}_{2}(\mathrm{LAI}-\mathrm{CCLIM})$, and (c) under constant CO ${ }_{2}\left(\mathrm{LAI}-\mathrm{CCO}_{2}\right)$ during 1950-2015. The box plot in the inset of (c) shows the global summary of climatology for LAI-HIST (1), LAI-CCLIM(2), and LAI-CCO 2 (3). (d)-(f) The change (significant at 95\%) of (a) LAI-HIST, (b) LAI-CCLIM and (c) LAI-CCO ${ }_{2}$ during 1950-2015. The box plot in the inset of (f) shows the global summary of the change (significant at 95\%) for LAI-HIST (1), LAI-CCLIM(2), and LAI-CCO 2 (3) during 1950-2015.

agricultural regions of India, China, USA, and Canada while a majority of the nonagricultural regions experienced an increase in day-time land surface temperature during 2003-2014.

- Among the four hydroclimatic variables, day and night-time land surface temperature are the two major contributors in the vegetation growth in about two-thirds of the global landmass. The assessment of the relative contribution of the four major hydroclimatic variables showed the importance of water availability on the vegetation growth in the agricultural areas of India, Russia, Argentina, Australia, and Africa. On the other hand, water availability does not considerably influence the vegetation growth in agricultural and nonagricultural regions of China

- The four hydroclimatic variables showed a higher relative contribution to NDVI in comparison to $\mathrm{CO}_{2}$ concentration due to detrending. The simulations obtained from the LUMIP for the three scenarios showed that $\mathrm{CO}_{2}$ concentration has a higher contribution on change in LAI than climate during the 2003-2014 and 1951-2015 period

- The lagged relationship of the hydroclimatic variables with the vegetation growth shows the potential of predictability in the agricultural and nonagricultural regions. However, the agricultural regions that experience significant human land management do not show a strong relationship between vegetation growth and hydroclimatic variables 
Our results showed the changes in the key hydroclimatic variables and vegetation growth during 2003-2014 in the global agricultural and nonagricultural areas. We find that the changes in agricultural and nonagricultural areas can differ considerably in the few regions primarily due to the strong influence of land management. While the increase in $\mathrm{CO}_{2}$ has been the major driver of vegetation growth in the past few decades as shown by the previous studies and LUMIP simulations, our results showed a weaker relationship between $\mathrm{CO}_{2}$ concentration and vegetation growth. The weak relationship between $\mathrm{CO}_{2}$ concentration and vegetation growth can be attributed to the removal of trends. Our findings have implications for developing vegetation growth monitoring systems using satellite-based observations.

\section{Data Availability Statement}

Authors acknowledge the data availability from AIRS; https://disc.gsfc.nasa.gov/datasets/AIRX3SPM_006/ summary, GRACE Tellus https://grace.jpl.nasa.gov/data/get-data/, MODIS/Aqua (MYD11CM1D); https:// disc.gsfc.nasa.gov/datasets/, MODIS/Aqua (MYDVI); https://disc.gsfc.nasa.gov/datasets/, and MODIS; https://landcover.usgs.gov/global_climatology.php, and LUMIP simulations from CMIP6; https://esgf-node.llnl.gov/search/cmip6/. All the datasets used in this study are freely available and can be downloaded. All the datasets used in the study are available on the links provided above. In addition, the datasets are available through the figshare link: https://doi.org/10.6084/m9.figshare.12981353.

\section{Acknowledgments}

The financial support from the Water Advanced Research and Innovation (WARI) Fellowship to the first Author is much appreciated. The Ministry of Earth Sciences partly supported this work.

\section{References}

AghaKouchak, A., Farahmand, A., Melton, F. S., Teixeira, J., Anderson, M. C., Wardlow, B. D., et al. (2015). Remote sensing of drought: Progress, challenges and opportunities. Reviews of Geophysics, 53(2), 452-480. https://doi.org/10.1002/2014RG000456

Alfaro, E. J., Gershunov, A., \& Cayan, D. (2006). Prediction of summer maximum and minimum temperature over the central and western United States: The roles of soil moisture and sea surface temperature. Journal of Climate, 19(8), 1407-1421. https://doi.org/10.1175/ JCLI3665.1

Asoka, A., Gleeson, T., Wada, Y., \& Mishra, V. (2017). Relative contribution of monsoon precipitation and pumping to changes in groundwater storage in India. Nature Geoscience, 10(2), 109-117. https://doi.org/10.1038/ngeo2869

Asoka, A., \& Mishra, V. (2015). Prediction of vegetation anomalies to improve food security and water management in India. Geophysical Research Letters, 42(13), 5290-5298. https://doi.org/10.1002/2015GL063991

Asoka, A., \& Mishra, V. (2020). Anthropogenic and climate contributions on the changes in terrestrial water storage in India. Journal of Geophysical Research: Atmosphere, 125(10), e2020JD032470. https://doi.org/10.1029/2020JD032470

Aumann, H. H., Chahine, M. T., Gautier, C., Goldberg, M. D., Kalnay, E., McMillin, L. M., et al. (2003). AIRS/AMSU/HSB on the Aqua mission: Design, science objectives, data products, and processing systems. IEEE Transactions on Geoscience and Remote Sensing, 41(2), 253-264. https://doi.org/10.1109/TGRS.2002.808356

$\mathrm{Bi}$, J. (2012). A review of statistical methods for determination of relative importance of correlated predictors and identification of drivers of consumer liking. Journal of Sensory Studies, 27(2), 87-101. https://doi.org/10.1111/j.1745-459X.2012.00370.x

Bonfils, C., \& Lobell, D. (2007). Empirical evidence for a recent slowdown in irrigation-induced cooling. Proceedings of the National Academy of Sciences, 104(34), 13582-13587. https://doi.org/10.1073/pnas.0700144104

Brown, M. E., de Beurs, K. M., \& Marshall, M. (2012). Global phenological response to climate change in crop areas using satellite remote sensing of vegetation, humidity and temperature over 26 years. Remote Sensing of Environment, 126, 174-183. https://doi.org/10.1016/j. rse.2012.08.009

Broxton, P. D., Zeng, X. Sulla-Menashe, D. \& Troch, P. A. (2014). A global land cover climatology using MODIS data. Journal of Applied Meteorology and Climatology, 53(6), 1593-1605. https://doi.org/10.1175/JAMC-D-13-0270.1

Chen, C., Park, T., Wang, X., Piao, S., Xu, B., Chaturvedi, R. K., et al. (2019). China and India lead in greening of the world through land-use management. Nature Sustainability, 2(2), 122-129. https://doi.org/10.1038/s41893-019-0220-7

FAO/IIASA. (2012). Global agro-ecological zones (GAEZ v3. 0). Italy, Laxenburg, Austria and FAO, IIASA. Retrieved from http://pure.iiasa. ac.at/13290

Farahmand, A., \& AghaKouchak, A. (2015). A generalized framework for deriving nonparametric standardized drought indicators. Advances in Water Resources, 76, 140-145. https://doi.org/10.1016/j.advwatres.2014.11.012

Farahmand, A., AghaKouchak, A., \& Teixeira, J. (2015). A vantage from space can detect earlier drought onset: An approach using relative humidity. Scientific Reports, 5, 8553. https://doi.org/10.1038/srep08553

Fosu, B. O., Wang, S.-Y. S., Wang, S.-H., Gillies, R. R., \& Zhao, L. (2017). Greenhouse gases stabilizing winter atmosphere in the Indo-Gangetic plains may increase aerosol loading: Greenhouse gases worsening aerosol loading in the IGP. Atmospheric Science Letters, 18(4), 168-174. https://doi.org/10.1002/asl.739

Friedl, M. A., Sulla-Menashe, D., Tan, B., Schneider, A., Ramankutty, N., Sibley, A., Huang, X., et al. (2010). MODIS Collection 5 global land cover: Algorithm refinements and characterization of new datasets. Remote Sensing of Environment, 114(1), 168-182. https://doi. org/10.1016/j.rse.2009.08.016

Funk, C. C., \& Brown, M. E. (2006). Intra-seasonal NDVI change projections in semi-arid Africa. Remote Sensing of Environment, 101(2), 249-256. https://doi.org/10.1016/j.rse.2005.12.014

Geruo, A., Velicogna, I., Kimball, J. S., \& Kim, Y. (2015). Impact of changes in GRACE derived terrestrial water storage on vegetation growth in Eurasia. Environmental Research Letters, 10(12), 124024. https://doi.org/10.1088/1748-9326/10/12/124024

Goldberg, M. D., Qu, Y., McMillin, L. M., Wolf, W., Zhou, L., \& Divakarla, M. (2003). AIRS near-real-time products and algorithms in support of operational numerical weather prediction. IEEE Transactions on Geoscience and Remote Sensing, 41(2), 379-389. https://doi.org/10.1109/TGRS.2002.808307 
Gonsamo, A., Chen, J. M., \& Lombardozzi, D. (2016). Global vegetation productivity response to climatic oscillations during the satellite era. Global Change Biology, 22(10), 3414-3426. https://doi.org/10.1111/gcb.13258

Grömping, U. (2006). Relative importance for linear regression in R: The package relaimpo. Journal of Statistical Software, 17(1). https:// doi.org/10.18637/jss.v017.i01

Han, S., \& Yang, Z. (2013). Cooling effect of agricultural irrigation over Xinjiang, Northwest China from 1959 to 2006. Environmental Research Letters, 8(2), 024039. https://doi.org/10.1088/1748-9326/8/2/024039

Hao, Z., AghaKouchak, A., Nakhjiri, N., \& Farahmand, A. (2014). Global integrated drought monitoring and prediction system. Scientific Data, 1, 140001. https://doi.org/10.1038/sdata.2014.1

Hatfield, J. L., \& Prueger, J. H. (2015). Temperature extremes: Effect on plant growth and development. Weather and Climate Extremes, 10, WACED1400046. https://doi.org/10.1016/j.wace.2015.08.001

Huete, A., Justice, C., \& Liu, H. (1994). Development of vegetation and soil indices for MODIS-EOS. Remote Sensing of Environment, 49(3), 224-234. https://doi.org/10.1016/0034-4257(94)90018-3

Keith, H., Mackey, B. G., \& Lindenmayer, D. B. (2009). Re-evaluation of forest biomass carbon stocks and lessons from the world's most carbon-dense forests. Proceedings of the National Academy of Sciences, 106(28), 11635-11640. https://doi.org/10.1073/pnas.0901970106

Kendall, M. G. (1975). Rank Correlation Methods (4th ed.), 8. Charles Griffin. Retrieved from https://www.worldcat.org/title/ rank-correlation-methods/oclc/3827024

Kogan, F., Adamenko, T., \& Guo, W. (2013). Global and regional drought dynamics in the climate warming era. Remote Sensing Letters, 4(4), 364-372. https://doi.org/10.1080/2150704X.2012.736033

Landerer, F. W., \& Swenson, S. C. (2012). Accuracy of scaled GRACE terrestrial water storage estimates: Accuracy of GRACE-TWS. Water Resources Research, 48(4), W04531. https://doi.org/10.1029/2011WR011453

Lawrence, D. M., Hurtt, G. C., Arneth, A., Brovkin, V., Calvin, K. V., Jones, A. D., et al. (2016). The land use model intercomparison project (LUMIP) contribution to CMIP6: Rationale and experimental design. Geoscientific Model Development, 9(9), 2973-2998. https://doi. org/10.5194/gmd-9-2973-2016

Lindeman, R. H., Merenda, P. F., \& Gold, R. Z. (1980). Introduction to bivariate and multivariate analysis. Scott Foresman, Texas, Dallas. Retrieved from http://www.sidalc.net/cgi-bin/wxis.exe/?IsisScript=COLPOS xis\&method $=$ post\&formato $=2 \&$ cantidad $=1 \&$ expresion $=\mathrm{mfn}=005517$

Long, D., Scanlon, B. R., Longuevergne, L., Sun, A. Y., Fernando, D. N., \& Save, H. (2013). GRACE satellite monitoring of large depletion in water storage in response to the 2011 drought in Texas. Geophysical Research Letters, 40(13), 3395-3401. https://doi.org/10.1002/ grl.50655

Los, S. O. (2013). Analysis of trends in fused AVHRR and MODIS NDVI data for 1982-2006: Indication for a CO ${ }_{2}$ fertilization effect in global vegetation: Trends in NDVI data. Global Biogeochemical Cycles, 27(2), 318-330. https://doi.org/10.1002/gbc.20027

Mann, H. B. (1945). Nonparametric tests against trend. Journal of the Econometric Society, 13(3), 245-259. https://doi.org/10.2307/1907187

Menzel, A., Sparks, T. H., Estrella, N., Koch, E., Aasa, A., Ahas, R., et al. (2006). European phenological response to climate change matches the warming pattern. Global Change Biology, 12(10), 1969-1976. https://doi.org/10.1111/j.1365-2486.2006.01193.x

Mildrexler, D. J., Zhao, M., \& Running, S. W. (2011). A global comparison between station air temperatures and MODIS land surface temperatures reveals the cooling role of forests. Journal of Geophysical Research, 116(G3). https://doi.org/10.1029/2010JG001486

Mueller, N. D., Butler, E. E., McKinnon, K. A., Rhines, A., Tingley, M., Holbrook, N. M., et al. (2015). Cooling of US Midwest summer temperature extremes from cropland intensification. Nature Climate Change, 6(3), 317-322. https://doi.org/10.1038/nclimate2825

Nemani, R. R., Keeling, C. D., Hashimoto, H., Jolly, W. M., Piper, S. C., Tucker, C. J., et al. (2003). Climate-driven increases in global terrestrial net primary production from 1982 to 1999. Science, 300(5625), 1560-1563. https://doi.org/10.1126/science.1082750

Peng, S., Piao, S., Ciais, P., Myneni, R. B., Chen, A., Chevallier, F., et al. (2013). Asymmetric effects of daytime and night-time warming on Northern Hemisphere vegetation. Nature, 501(7465), 88-92. https://doi.org/10.1038/nature12434

Peng, S.-S., Piao, S., Zeng, Z., Ciais, P., Zhou, L., Li, L. Z. X., et al. (2014). Afforestation in China cools local land surface temperature. Proceedings of the National Academy of Sciences, 111(8), 2915-2919. https://doi.org/10.1073/pnas.1315126111

Piao, S., Wang, X., Park, T., Chen, C., Lian, X., He, Y., et al. (2020). Characteristics, drivers and feedbacks of global greening. Nature Reviews Earth \& Environment, 1(1), 14-27. https://doi.org/10.1038/s43017-019-0001-X

Rodell, M., Famiglietti, J. S., Wiese, D. N., Reager, J. T., Beaudoing, H. K., Landerer, F. W., et al. (2018). Emerging trends in global freshwater availability. Nature, 557(7707), 651-659. https://doi.org/10.1038/s41586-018-0123-1

Rodell, M., Velicogna, I., \& Famiglietti, J. S. (2009). Satellite-based estimates of groundwater depletion in India. Nature, 460(7258), 9991002. https://doi.org/10.1038/nature08238

Schmidhuber, J., \& Tubiello, F. N. (2007). Global food security under climate change. Proceedings of the National Academy of Sciences, 104(50), 19703-19708. https://doi.org/10.1073/pnas.0701976104

Schneider, T., O'Gorman, P. A., \& Levine, X. J. (2010). Water vapor and the dynamics of climate changes. Reviews of Geophysics, 48(3). https://doi.org/10.1029/2009RG000302

Seddon, A. W. R., Macias-Fauria, M., Long, P. R., Benz, D., \& Willis, K. J. (2016). Sensitivity of global terrestrial ecosystems to climate variability. Nature, 531(7593), 229-232. https://doi.org/10.1038/nature16986

Sen, P. K. (1968). Estimates of the regression coefficient based on Kendall's tau. Journal of the American Statistical Association, 63(324), 1379-1389. https://doi.org/10.1080/01621459.1968.10480934

Seneviratne, S. I., Lüthi, D., Litschi, M., \& Schär, C. (2006). Land-atmosphere coupling and climate change in Europe. Nature, 443(7108), 205-209. https://doi.org/10.1038/nature05095

Sheffield, J., Goteti, G., \& Wood, E. F. (2006). Development of a 50-year high-resolution global dataset of meteorological forcings for land surface modeling. Journal of Climate, 19(13), 3088-3111. https://doi.org/10.1175/JCLI3790.1

Silber, J. H., Rosenbaum, P. R., \& Ross, R. N. (1995). Comparing the contributions of groups of predictors: Which outcomes vary with hospital rather than patient characteristics? Journal of the American Statistical Association, 90(429), 7-18. https://doi.org/10.2307/2291124

Sun, H., Zhao, X., Chen, Y., Gong, A., \& Yang, J. (2013). A new agricultural drought monitoring index combining MODIS NDWI and day-night land surface temperatures: a case study in China. International Journal of Remote Sensing, 34(24), 8986-9001. https://doi.or g/10.1080/01431161.2013.860659

Thompson, M. V., Randerson, J. T., Malmström, C. M., \& Field, C. B. (1996). Change in net primary production and heterotrophic respiration: How much is necessary to sustain the terrestrial carbon sink? Global Biogeochemical Cycles, 10(4), 711-726. https://doi. org/10.1029/96GB01667

Tian, B., Manning, E., Fetzer, E., Olsen, E., Wong, S., Susskind, J., et al. (2013). AIRS/AMSU/HSB version 6 level 3 product user guide. Jet Propulsion Laboratory, Pasadena, CA. Retrieved from https://science.jpl.nasa.gov/people/Tian/ 
Tibbitts, T. W. (1979). Humidity and plants. BioScience, 29(6), 358-363. https://doi.org/10.2307/1307692

van den Hurk, B., Kim, H., Krinner, G., Seneviratne, S. I., Derksen, C., Oki, T., et al. (2016). LS3MIP (v1.0) contribution to CMIP6: The land surface, snow and soil moisture model intercomparison project: Aims, setup and expected outcome. Geoscientific Model Development, 9(8), 2809-2832. https://doi.org/10.5194/gmd-9-2809-2016

Velicogna, I., Kimball, J. S., \& Kim, Y. (2015). Impact of changes in GRACE derived terrestrial water storage on vegetation growth in Eurasia. Environmental Research Letters, 10(12), 124024. https://doi.org/10.1088/1748-9326/10/12/124024

Vicente-Serrano, S. M., Gouveia, C., Camarero, J. J., Begueria, S., Trigo, R., Lopez-Moreno, J. I., et al. (2013). Response of vegetation to drought time-scales across global land biomes. Proceedings of the National Academy of Sciences, 110(1), 52-57. https://doi.org/10.1073/ pnas. 1207068110

Willett, K. M., Gillett, N. P., Jones, P. D., \& Thorne, P. W. (2007). Attribution of observed surface humidity changes to human influence. Nature, 449(7163), 710. https://doi.org/10.1038/nature06207

Wu, D., Zhao, X., Liang, S., Zhou, T., Huang, K., Tang, B., et al. (2015). Time-lag effects of global vegetation responses to climate change. Global Change Biology, 21(9), 3520-3531. https://doi.org/10.1111/gcb.12945

Xie, X., He, B., Guo, L., Miao, C., \& Zhang, Y. (2019). Detecting hotspots of interactions between vegetation greenness and terrestrial water storage using satellite observations. Remote Sensing of Environment, 231, 111259. https://doi.org/10.1016/j.rse.2019.111259

Yang, Y., Long, D., Guan, H., Scanlon, B. R., Simmons, C. T., Jiang, L., et al. (2014). GRACE satellite observed hydrological controls on interannual and seasonal variability in surface greenness over mainland Australia. Journal of Geophysical Research: Biogeosciences, 119(12), 2014JG002670. https://doi.org/10.1002/2014JG002670

Zeng, Z., Piao, S., Li, L. Z. X., Zhou, L., Ciais, P., Wang, T., et al. (2017). Climate mitigation from vegetation biophysical feedbacks during the past three decades. Nature Climate Change, 7(6), 432-436. https://doi.org/10.1038/nclimate3299

Zhao, L., Dai, A., \& Dong, B. (2018). Changes in global vegetation activity and its driving factors during 1982-2013. Agricultural and Forest Meteorology, 249, 198-209. https://doi.org/10.1016/j.agrformet.2017.11.013

Zhao, M., \& Running, S. W. (2010). Drought-induced reduction in global terrestrial net primary production from 2000 through 2009. Science, 329(5994), 940-943. https://doi.org/10.1126/science.1192666

Zhu, Z., Piao, S., Myneni, R. B., Huang, M., Zeng, Z., Canadell, J. G., et al. (2016). Greening of the Earth and its drivers. Nature Climate Change, 6(8), 791-795. https://doi.org/10.1038/nclimate3004 